\title{
Strong and ductile heat-treatable Mg-Sn-Zn-Al wrought alloys
}

\author{
T. T. Sasaki ${ }^{1)}$, F.R. Elsayed ${ }^{1,2)}$, T. Nakata ${ }^{3)}$, T. Ohkubo ${ }^{1)}$, S. Kamado ${ }^{3)}$, and K. Hono ${ }^{1,2)}$ \\ ${ }^{1)}$ National Institute for Materials Science, 1-2-1 Sengen, Tsukuba, 305-0047, Japan \\ ${ }^{2)}$ Graduate school of pure and applied science, University of Tsukuba, 1-1 Tenno-dai, Tsukuba, \\ 305-0001, Japan \\ ${ }^{3)}$ Nagaoka University of Technology, 1603-1, Kamitomioka, Nagaoka, 940-2188, Japan \\ Contact author: SASAKI.Taisuke@nims.go.jp
}

Keywords: Mg-Sn, Precipitation hardening, Extrusion, Microalloying

\begin{abstract}
A newly developed Mg-Sn-Zn-Al based alloy shows substantial strengthening by artificial aging. A Na-doped Mg-5.4Sn-4.2Zn-2.0Al-0.2Mn-0.1Na (TZAM5420-0.1Na) (wt\%) alloy exhibited a significant increase in yield strength from 243 to $347 \mathrm{MPa}$ by a T6 treatment due to the uniform dispersion of nanoscale precipitates by aging. The trace addition of $\mathrm{Na}$ causes the formation of Sn-Na co-clusters in the early stage of aging, which provides heterogeneous nucleation sites for $\mathrm{Mg}_{2} \mathrm{Sn}$ precipitates. However, $\mathrm{Na}$ strongly segregates at grain boundaries and this degrades the ductility significantly. To overcome this problem, we developed a Na-free Mg-6.6Sn-5.9Zn-2.0Al-0.2Mn (TZAM6620) alloy, in which nano-scale $\mathrm{MgZn}_{2}$ precipitates are uniformly dispersed by double aging. Pre-aging caused the formation of $\mathrm{Zn}$-rich Guinier Preston zones, which acted as heterogeneous nucleation sites for the $\mathrm{MgZn}_{2}$ precipitates. The double-aged TZAM6620 alloy exhibited a very high yield strength of 370 MPa with large elongation of $14 \%$.
\end{abstract}




\section{Introduction}

The development of high strength wrought magnesium alloys is strongly desired for transportation vehicles to improve their fuel efficiencies by weight reduction. While the grain refinement by severe plastic deformation and slow-speed extrusion can induce high yield strengths over $300 \mathrm{MPa}$ in various magnesium based alloys such as Mg-Al-Zn (AZ) [1-5], $\mathrm{Mg}-\mathrm{Zn}-\mathrm{Zr}(\mathrm{ZK})$ [6-8] and Mg-Sn (T) based alloys [9-11], the strengthening is achieved at the expense of ductility and formability due to their work hardened nature. On the other hand, precipitation hardenable alloys are formable after a solution treatment if recrystallized microstructure is optimized, and the final product can be strengthened by artificial aging [12]. Such a heat-treatable wrought magnesium alloy was demonstrated in the $\mathrm{Mg}-\mathrm{Zn}$ based alloy microalloyed with Ag, Ca and Zr, ZKQX6000 [12]. More recently, Bhattacharjee et al. reported an equivalent mechamical properties even without the addition of expensive $\mathrm{Ag}$ [13].

The Mg-Sn system is precipitation-hardenable since the solubility of $\mathrm{Sn}$ decreases with temperature [14]. However, little work has been done on the precipitation strengthening of Mg-Sn wrought alloys. Unlike the Mg-Al-Zn (AZ) and Mg-Zn-Zr (ZK) alloys [15], the $\mathrm{Mg}-\mathrm{Sn}$ alloys are softened when artificially aged directly after extrusion since coarse $\mathrm{Mg}_{2} \mathrm{Sn}$ particles dynamically precipitate during hot-extrusion [16]. The artificial aging after a solution treatment (T6) does not induce significant strengthening to the $\mathrm{Mg}$-Sn wrought alloy either [17], because the solution treatment above $500{ }^{\circ} \mathrm{C}$ leads to a rapid grain growth. To develop heat-treatable $\mathrm{Mg}$-Sn based alloys, the poor age hardening response needs to be improved and the rapid grain growth during the solution treatment must be controlled [17-26].

Recently, Elsayed et al. demonstrated the significant age hardening response that reached to a peak hardness of over $100 \mathrm{VHN}$ in a Mg-9.8Sn-3.0Al-1.0Zn-0.1Na (TZA1031-0.1Na) cast alloy [27]. Although such a significant age hardening is expected to strengthen the 
extruded sample by the T6 treatment, the Na-doped TAZ1031 extruded alloy exhibited very limited ductility because of the $\mathrm{Na}$ segregation at grain boundaries [10]. In this work, we thoroughly investigated the role of microalloyed $\mathrm{Na}$ on the mechanical property and microstructure evolution during the T6 treatment of a new series of alloys, Mg-5.4Sn-4.3Zn-2.0Al (TZA542). The TZA542 and similar alloys exhibit the age hardening response as high as the previously reported TAZ1031 alloys [22, 25, 28]. We expected this low Sn alloy would be more suitable as wrought material than the TAZ1031 based alloys. Since it can be solution treated at a lower temperature compared to the TAZ1031 alloy due to the lower Sn concentration, the rapid grain growth during the solution treatment could be controlled [14]. Based on the strengthening mechanism by the $\mathrm{Na}$ addition determined by atom probe tomography (APT) and transmission electron microscopy, we have developed a Na-free Mg-Sn-Zn-Al extruded alloy by optimizing the composition and heat treatment process. The newly developed Na-free Mg-6.6Sn-5.9Zn-2.0Al-0.2Mn (TZAM6620) alloy exhibited an extraordinary high yield strength over $370 \mathrm{MPa}$ along with the elongation to failure of $14 \%$ by the introduction of duplex aging that induces heterogeneous nucleation sites for precipitates.

\section{Experimental Procedure}

Alloy ingots were prepared by induction melting using steel crucibles under an Ar atmosphere and casting into iron molds. Table 1 summarizes their alloy nomenclatures and chemical compositions in both wt.\% and at.\%. Mn was added as a grain growth inhibitor during the solution treatment [29-31]. The cast ingots were homogenized at $450{ }^{\circ} \mathrm{C}$ for $24 \mathrm{~h}$ in an $\mathrm{Ar}$ atmosphere followed by quenching into water. The samples were extruded at $300{ }^{\circ} \mathrm{C}$ with the ram speed of 2 and $0.1 \mathrm{~mm} / \mathrm{s}$ and an extrusion ratio of 20 . The extruded samples 
were subjected to the T6 treatment consisting of the solution treatment in an electric furnace and aging in an oil bath at various conditions. The age hardening responses were measured by the Vickers hardness tests under a load of $500 \mathrm{~g}$. Mechanical properties were evaluated by tensile tests at an initial strain rate of $1.0 \times 10^{-3} \mathrm{~s}^{-1}$ using round bar specimens with the diameter and gauge length of 4 and $22 \mathrm{~mm}$.

Microstructure characterization was performed by Auger electron spectroscopy (AES), scanning electron microscope (SEM), transmission electron microscope (TEM) and 3D atom probe (3DAP). Auger spectroscopy was done using ULVAC-PHI, PHI 680 operating at $10 \mathrm{kV}$. The round bar sample with $\mathrm{V}$-notch was fractured at a cryogenic temperature in an ultra-high vacuum atmosphere, and Auger spectra were acquired from the fractured surface. SEM observations with energy dispersive spectroscopy (EDS) were performed using a field emission SEM, FEI Helios Nanolab 650, equipped with Bruker EDS detector. Electron backscattered diffraction (EBSD) analyses were done using a field emission SEM, Carl Zeiss Cross Beam 1540EsB, equipped with a HKL EBSD system and CHANNEL 5 software. TEM observation was carried out using FEI Tecnai 20 and Titan G2 80-200 TEMs. Thin foils for the TEM observation were prepared by punching $3 \mathrm{~mm}$ diameter discs, mechanical polishing and ion-milling using a Gatan Precision Ion Polishing System (PIPS). 3DAP analyses or atom probe tomography (APT) were carried out with a locally built laser-assisted wide-angle atom probe (LAWATAP) using a femtosecond laser pulse at a wavelength of $343 \mathrm{~nm}$. Square bars with dimensions of $0.5 \times 0.5 \times 15 \mathrm{~mm}^{3}$ were cut from bulk samples and electropolished to prepare sharp and needle-like specimens. The 3DAP analyses were performed in an ultra-high vacuum condition $\left(<1.0 \times 10^{8} \mathrm{~Pa}\right)$ at a base temperature of $20 \mathrm{~K}$. 


\section{Results}

Figure 1 (a) shows variations in Vickers hardness values of TZA542, TZAM5420, TZA542-0.1Na and TZAM5420-0.1 Na alloys as functions of aging time. After a solution treatment and quenching (T4 treatment), the Vickers hardness values decrease to $\sim 55 \mathrm{VHN}$ for all the samples. The hardness starts to increase significantly after $6 \mathrm{~h}$ aging at $160^{\circ} \mathrm{C}$. While the hardness reaches a peak after $300 \mathrm{~h}$ for both TZA542 and TZAM5420, the addition of Mn to the TZA542 alloy decreases the peak hardness from $74.2 \pm 1.7$ to $65.7 \pm 1.8 \mathrm{VHN}$. The trace addition of Na to the TZA542 and TZAM5420 alloys substantially increases the peak hardness value to $92.2 \pm 2.5$ and $92.9 \pm 2.5 \mathrm{VHN}$, and the peak aging time was shortened to 100 h.

Figure 1 (b) shows the age-hardening curves of TZA542, TZA562 and TZAM6620 alloys with different solution treatment and aging temperatures. The age-hardening curves for the TZA542 alloy solution treated at $350^{\circ} \mathrm{C}$ and $450^{\circ} \mathrm{C}$ for $0.25 \mathrm{~h}$ shows that the decrease in hardness is suppressed at the solution treatment temperature of $350^{\circ} \mathrm{C}$. Hereafter, only the results of the samples solution treated at $350^{\circ} \mathrm{C}$ are discussed. TZA542 alloy shows the peak hardness of $73.1 \pm 1.3 \mathrm{VHN}$ after aging for $100 \mathrm{~h}$ at $160^{\circ} \mathrm{C}$. The TZA562 alloy that contains a higher amount of $\mathrm{Zn}$ by $2 \mathrm{wt} . \%$, reaches a higher peak hardness of $81.3 \pm 1.8 \mathrm{VHN}$ after $30 \mathrm{~h}$ aging at $160^{\circ} \mathrm{C}$. This peak aging time is only one third of that of the TZA542 alloy. The peak hardness further increases to $86.2 \pm 3.1 \mathrm{VHN}$ with decreasing the aging temperature to $140^{\circ} \mathrm{C}$ while the time to reach the peak hardness is delayed to $160 \mathrm{~h}$. Interestingly, the double aging consisting of the pre-aging at $70^{\circ} \mathrm{C}$ for $150 \mathrm{~h}$ and the second aging at $140^{\circ} \mathrm{C}$ lead to a substantial increase in the peak hardness of the TZA562 alloy. After the pre-aging at $70^{\circ} \mathrm{C}$ for $150 \mathrm{~h}$, the hardness increased to $80.7 \pm 1.3 \mathrm{VHN}$. When this pre-aged sample was double-aged at $140^{\circ} \mathrm{C}$, the age hardening response was substantially enhanced compared to the single-aged 
sample with the peak hardness of $99.0 \pm 1.2 \mathrm{VHN}$ after $30 \mathrm{~h}$ aging. The addition of $1 \mathrm{wt} . \% \mathrm{Sn}$ and 0.5 wt.\% Mn to TZA562 alloy, i.e. TZAM6620 alloy, resulted in a slight increase in peak hardness to $89.7 \pm 1.0 \mathrm{VHN}$ by single aging at $140^{\circ} \mathrm{C}$ compared to the TZA562 alloy single aged at $140^{\circ} \mathrm{C}$. By double aging the TZAM6620 alloy at $70^{\circ} \mathrm{C}$ for $150 \mathrm{~h}$ and $140^{\circ} \mathrm{C}$, the TZAM6620 alloy showed the highest peak hardness of $102.1 \pm 1.0 \mathrm{VHN}$. Note that the hardness exceeding $100 \mathrm{HVN}$ is not commonly observed in magnesium alloys without rare earth elements, suggesting TZAM6620 has potential to show high strength with an optimal heat treatment.

Figures 2 (a) and (b) show tensile and compressive stress-strain curves of the TZA542, TZAM5420, TZA542-0.1 Na and TZAM5420-0.1Na alloys in the as-extruded and peak aged conditions. Table 2 summarizes their tensile yield strength, $\sigma_{T Y S}$, ultimate tensile strength, $\sigma_{U T S}$, and elongation to failure, $\varepsilon_{T}$, compressive yield strength, $\sigma_{C Y S}$, compressive strength, $\sigma_{C S}$, and compressive strain, $\varepsilon_{C}$. While the as-extruded TZA542 and TZAM5420 alloys exhibit similar $\sigma_{T Y S}$ of 184 and $182 \mathrm{MPa}$, the TZAM5420 alloy shows larger $\varepsilon$ of $24 \%$ compared to that of the TZA542 alloy, $11 \%$ as shown in Fig. 2 (a). In compression, the as-extruded TZA542 and TZAM5420 alloys exhibit $\sigma_{C Y S}$ of 170 and $168 \mathrm{MPa}$. The extruded alloys show low yield asymmetry of a tension to compression ratio, $\sigma_{C Y S} / \sigma_{T Y S}$, of 0.9 . By the T6 treatment, the TZA542 and TZAM5420 alloys show only a slight increase in $\sigma_{Y S}$; the $\sigma_{Y S}$ of the TZA542 and TZAM5420 alloys increase to 228 and $186 \mathrm{MPa}$ at the expense of $\varepsilon_{T}$. The T6 treated TZAM5420 alloy shows even larger elongation, $\varepsilon$, of $15 \%$ compared to that of the T6 treated TZA542 alloy, 6\%. However, $\sigma_{C Y S}$ of the TZA542 and TZAM5420 decrease to 141 and $142 \mathrm{MPa}$ resulting in higher yield asymmetry with $\sigma_{C Y S} / \sigma_{T Y S}$, of 0.62 and 0.76 compared to the as-extruded alloys. The as-extruded TZA542-0.1 Na and TZAM5420-0.1Na alloys 
exhibit $\sigma_{T Y S}$ of 203 and $243 \mathrm{MPa}$ and $\sigma_{C Y S}$ of 197 and $245 \mathrm{MPa}$, which are slightly higher compared to those of the as-extruded TZA542 and TZAM5420 alloys. The as-extruded TZA542-0.1Na and TZAM5420-0.1Na alloys also show low yield asymmetry with $\sigma_{C Y S} / \sigma_{T Y S}$, of 0.97 and 1.01, respectively. The TZA542-0.1Na and TZAM5420-0.1 Na alloys exhibit larger increase in $\sigma_{T Y S}$ by $\mathrm{T} 6$ treatment compared to the TZA542 and TZAM5420 alloys. TZA542-0.1Na alloy shows the increase in $\sigma_{T Y S}$ from 203 to $257 \mathrm{MPa}$ by a T6 heat treatment. However, the T6 heat treatment results in significant loss of $\varepsilon_{T}$ to only 0.03 for both TZA542-0.1 Na and TZAM5420-0.1 Na alloys. The T6 treatment also resulted in the increase in yield asymmetry with $\sigma_{C Y S} / \sigma_{T Y S}$, of 0.78 and 0.65 for TZA542-0.1 Na and TZAM5420-0.1Na since $\sigma_{C Y S}$ shows only a slight increase or decrease by the T6 treatment.

Figure 2 (c) and (d) show the tensile and compressive stress-strain curves of as-extruded and peak aged TZA562 and TZAM6620 alloys. Table 3 summarizes their tensile yield strength, $\sigma_{T Y S}$, ultimate tensile strength, $\sigma_{U T S}$, and elongation to failure, $\varepsilon_{T}$, compressive yield strength, $\sigma_{C Y S}$, compressive strength, $\sigma_{C S}$, and compressive strain, $\varepsilon_{C}$. The as-extruded TZAM562 alloy exhibits $\sigma_{T Y S}$ and $\sigma_{C Y S}$ of 243 and $234 \mathrm{MPa}$ with low yield asymmetry of $\sigma_{C Y S} / \sigma_{T Y S}$, of 0.96 as well as the other extruded alloys. Although the $\sigma_{T Y S}$ and $\sigma_{C Y S}$ show only a slight increase to 255 and $237 \mathrm{MPa}$ by the artificial aging at $140^{\circ} \mathrm{C}$ for $100 \mathrm{~h}$, the double-aging results in a substantial increase in $\sigma_{T Y S}$ and $\sigma_{C Y S}$ to 346 and $277 \mathrm{MPa}$ without significant loss of ductility, $\varepsilon_{T}=15 \%$ unlike Na-containing alloys. The TZA562 alloy keeps low yield asymmetry of $\sigma_{C Y S} / \sigma_{T Y S}$, of 0.93 and 0.80 after peak aging at $140^{\circ} \mathrm{C}$ and double aging. The addition of $1 \mathrm{wt} . \%$ of $\mathrm{Sn}$ and $0.5 \mathrm{wt} . \%$ of Mn results in further increase in the strength. The as-extruded TZAM6620 alloy exhibits $\sigma_{T Y S}$ and $\sigma_{C Y S}$ of 247 and $253 \mathrm{MPa}$ with low yield asymmetry of $\sigma_{C Y S} / \sigma_{T Y S}$, of 1.02 as well as the other extruded alloys. As well as the TZA562 
alloy, the double-aging results in a substantial increase in $\sigma_{T Y S}$ and $\sigma_{C Y S}$ to 370 and $307 \mathrm{MPa}$ keeping low yield asymmetry of $\sigma_{C Y S} / \sigma_{T Y S}$, of 0.83 while the artificial aging at $140^{\circ} \mathrm{C}$ showed only a slight increase in the strength. Both single aged and double aged TZAM6620 show large ductility, $\varepsilon_{T}$, of 13 and $14 \%$ compared to T6 treated Na-containing alloys.

Figure 3 (a) - (d) are inverse pole figure (IPF) maps obtained from the as-extruded TZA542, TZAM5420, TZAM5420-0.1Na and TZAM6620 alloys taken from the planes parallel to the extrusion direction. The as-extruded samples exhibit the bimodal grain structure consisting of fine and equi-axed recrystallized grains, and coarse un-recrystallized grains elongated along the extrusion direction. While the recrystallized grains in the as-extruded TZA542 and TZAM5420 alloys have similar average grain sizes of 4.5 and $4.9 \mu \mathrm{m}$, Fig. 3 (a) and (b), the trace addition of $\mathrm{Na}$ leads to the refinement of the recrystallized grains to $2.5 \mu \mathrm{m}$, Fig. 3 (c). The recrystallized grains in the TZAM6620 alloy have the average size of $1.6 \mu \mathrm{m}$, which is finer than those of the TZA542, TZAM5420 and TZAM5420-0.1Na alloys because of the slow extrusion speed as expected from the previous work $[10,11]$. The insets to Fig. 3 (a) - (d) show the (0001) pole figures analyzed from the plane normal to the extrusion direction. They show the alignment of [0001] direction to the radial direction of the extruded bars, which is typical for extruded magnesium alloys.

After the solution treatment, the grains are fully recrystallized as shown in the IPF maps of the solution treated samples, Fig. 3 (e) - (h). After the solution treatment at $450{ }^{\circ} \mathrm{C}$, the grains in the TZA542 alloy are coarsened to $89.5 \mu \mathrm{m}$, while those in the TZAM5420 and TZAM5420-0.1Na alloys have finer grain structure with the size of 35.5 and $25.3 \mu \mathrm{m}$. The TZAM6620 alloy solution treated at $350{ }^{\circ} \mathrm{C}$ keeps the finest grain size of $7.8 \mu \mathrm{m}$. The textured feature in the solution-treated TZA542 and TZAM5420 alloys were difficult to characterize because of the limited number of grains within the field of view. However, since 
the (0001) pole figures analyzed from the solution treated TZAM5420-0.1Na and TZAM6620 alloys show the alignment of [0001] directions to the radial direction of the extruded bars as seen from the inset to Fig. 3 (g) and (h), the typical ring extruded texture observed in the as-extruded conditions still remains after the solution treatment.

Figure 4 (a) is a backscattered electron SEM image obtained from the solution treated TZAM5420-0.1 Na alloy. Due to the channeling contrast, individual grains are visible. Secondary phases are located along the grain boundaries as indicated by arrows. The corresponding EDS elemental map of Sn, Al and Mn, Fig. 4 (b), shows that some are enriched in $\mathrm{Sn}$, and others are enriched in $\mathrm{Al}$ and Mn. Figure 4 (c) shows a fractured surface of the solution treated TZA542-0.1 Na alloy showing brittle fractured feature at the grain boundaries. The Auger spectrum obtained from the fractured surface, Fig. 4 (d), shows a peak corresponding to $\mathrm{Na}$ at $993 \mathrm{eV}$ as well as those from $\mathrm{Mg}, \mathrm{Sn}$ and $\mathrm{O}$, indicating the $\mathrm{Na}$ segregation at the grain boundaries. Figure 4 (e) show bright field TEM image taken from the TZAM6620 alloy solution treated at $350{ }^{\circ} \mathrm{C}$. Spherical precipitates with the size of $211.0 \pm$ $18.0 \mathrm{~nm}$ are densely observed along the grain boundaries and grain interiors compared to those in TZAM5420-0.1 Na alloy solution treated at $450^{\circ} \mathrm{C}$. A micro-beam diffraction pattern taken from one of the spherical precipitates identified them as the $\mathrm{Mg}_{2} \mathrm{Sn}$ phase, Fig. 4 (f).

Figure 5 (a) and (b) show the bright field TEM images of the T6-treated TZA542 alloy taken from the zone axes of [01 10$]$ and [0001]. Precipitates are heterogeneously dispersed within the matrix. As shown in Fig. 5 (b), a part of blocky precipitates are linearly aligned along the $[10 \overline{1} 0]$ direction, while the others are heterogeneously dispersed within the grain. The blocky precipitates were identified as $\beta_{2}$ ' phase $[28,32]$, and their average size was $55.2 \pm 3.9,41.7 \pm 3.2$ and $26.0 \pm 2.3 \mathrm{~nm}$ in length, width and height. The coarse lath shaped precipitates also form on the (0001) plane of the magnesium matrix. They are the $\mathrm{Mg}_{2} \mathrm{Sn}$ 
phase [14], which grows along the [112̄0] direction with the size of $190 \pm 13.9,53 \pm 5.2$ and $68.3 \pm 7.7 \mathrm{~nm}$ in length, width and thickness. Figure 5 (c) and (d) show the bright field TEM images of the peak-aged TZAM5420-0.1Na alloy at $160{ }^{\circ} \mathrm{C}$. Note that these images were taken from the zone axes of [11̄20] and [0001]. The precipitates are much finer and uniformly dispersed compared to those in the peak-aged TZA542 alloy. The precipitates are the lath shape with the size of $33.9 \pm 6.29,14.5 \pm 3.0$ and $13.7 \pm 2.7 \mathrm{~nm}$ in length, width and height, and form on the (0001) plane of the magnesium matrix.

As shown in the HAADF-STEM image taken from the zone axis of [11̄0] (Figure 6 (a)), the two precipitates indicated by arrowhead are in contact with each other in the peak aged TZAM5420-0.1Na alloy. Fig. 6 (b) and (c) are micro-beam diffraction patterns obtained from the two precipitates indicated by black and white arrows in Fig. 6 (a). Note that these patterns were taken from the zone axis of [1010] for easy visualization of diffraction spots. These precipitates were identified as the $\mathrm{Mg}_{2} \mathrm{Sn}$ and $\beta_{2}$ ' phases. However, Fig. 5 (a) does not show whether or not the $\mathrm{Mg}_{2} \mathrm{Sn}$ and $\beta_{2}$ ' phases are indirect contact with each other. To clarify this, 3D atom probe analysis was performed. The 3D atom map (Fig. 5 (d)) and ladder diagram taken from the volume in Fig. 5 (d) (Fig. 5 (e)) clearly confirm these precipitates are in direct contact with each other.

Figure 7 (a) and (b) show the bright field TEM images of the TZAM6620 alloy peak aged at $140^{\circ} \mathrm{C}$. These images were taken along the zone axes of [0110] and [0001]. Two kinds of precipitates are observed; one is rod-like precipitates grown along the [0001] direction, and the other is blocky ones on the (0001) plane. The [0001] rods have the average size of $247 \pm 16.4$ and $12.5 \pm 2.8 \mathrm{~nm}$ in length and diameter, and they are uniformly dispersed within the matrix phase. The blocky precipitates have the size of $20.1 \pm 2.1$ and $15.4 \pm 1.9 \mathrm{~nm}$ in diameter and thickness, and they are heterogeneously dispersed within the matrix. Figure 7 
(c) and (d) are microbeam diffraction patterns obtained from a [0001] rod and blocky precipitates. They are identified as $\beta_{1}{ }^{\prime}$ and $\beta_{2}{ }^{\prime}$ phases, which are typically observed in $\mathrm{Mg}-\mathrm{Zn}$ based alloys. The $\beta_{1}$ ' phase has the orientation relationship (OR) with the magnesium matrix described as $(2 \overline{1} \overline{1} 0)_{\beta_{1}^{\prime}} / /(0001)_{M g},[0001]_{\beta_{1}^{\prime}} / /[2 \overline{1} \overline{1} 0]_{M g}$, and the $\beta_{2}{ }^{\prime}$ phases have the OR of $(0001)_{\beta_{2}^{\prime}} / /(0001)_{M g}$ and $[11 \overline{2} 0]_{\beta_{2}^{\prime}} / /[10 \overline{1} 0]_{M g}$ as reported previously [32-35]. The double-aging results in the significant refinement of these precipitates as shown in Fig. 7 (e) and (f). The size of the [0001] rod is $24.6 \pm 1.3$ and $4.8 \pm 0.5 \mathrm{~nm}$ in length and diameter, and the diameter and thickness of the blocky precipitate is $20.1 \pm 2.1$ and $15.4 \pm 1.9 \mathrm{~nm}$, respectively.

Figure 8 (a) shows HAADF-STEM image of the TZAM5420-0.1Na alloy aged for 6 $\mathrm{h}$ at $160{ }^{\circ} \mathrm{C}$. The images were observed along the zone axis of [1120]. A lot of brightly imaged dotty contrasts are observed, indicating the enrichment of the alloying elements heavier than $\mathrm{Mg}$, i.e., $\mathrm{Zn}$ or $\mathrm{Sn}$, as indicated by black arrows, while there are also a few coarse lath-shaped precipitates as indicated by white arrows. As shown in the magnified HAADF-STEM image in the inset to Fig. 8 (a), the dotty contrast has the diameter of $\sim 4 \mathrm{~nm}$ with coherent interface with the Mg matrix. Figure 8 (b) shows a 3D atom map obtained from the TZAM5420-0.1 Na alloy aged at $160^{\circ} \mathrm{C}$ for $6 \mathrm{~h}$. Na-enriched regions are recognized from the density of $\mathrm{Na}$ atoms. For better visualization of the Na-enriched regions, one of the Na-enriched regions is displayed using an isoconcentration surface of 0.4 at.\% Na. Figure 8 (c) shows a ladder diagram analyzed from a selected volume in Fig. 8 (b). The composition of the Na-enriched volume was calculated as Mg-12.04Sn-0.75Zn-1.1Al-1.9Na (at.\%), which means the formation of $\mathrm{Sn}-\mathrm{Na}$ co-cluster at $6 \mathrm{~h}$.

The extended aging for $16 \mathrm{~h}$ resulted in the precipitation of lath shaped precipitates as indicated by white arrows in the HAADF-STEM image in Fig. 9 (a). Figure 9 (b) shows 
the $3 \mathrm{D}$ atom map obtained from the same sample. In addition to the Na-enriched particles, a lot of Sn-enriched regions are observed, and it looks like that they are in contact with the Sn-Na co-clusters. The Sn iso-concentration surface with the concentration of 14.5 at.\% visualize one of the Sn-enriched precipitates. Fig. 9 (c) shows the ladder diagram analyzed from the selected volume with light blue. The composition of the Sn-enriched volume is calculated as $\mathrm{Mg}-31.3 \mathrm{Sn}-1.3 \mathrm{Zn}-1.4 \mathrm{Al}-0.03 \mathrm{Na}$ (at.\%), which is consistent with the $\mathrm{Mg}_{2} \mathrm{Sn}$ phase. Interestingly, the concentration of $\mathrm{Zn}, \mathrm{Al}$ and $\mathrm{Na}$ at a $\mathrm{Mg}_{2} \mathrm{Sn} / \mathrm{Mg}$ interface is $9.7,5.0$ and 0.0 at.\% showing the segregation of $\mathrm{Zn}$ and Al. Fig. 9 (d) also shows the ladder diagram including the $\mathrm{Mg}_{2} \mathrm{Sn} /$ matrix interface analyzed from the selected volume with pink in Fig. 9 (b), which confirms the $\mathrm{Mg}_{2} \mathrm{Sn}$ particle is in direct contact with the Na cluster.

Figure 10 (a) shows the bright field TEM image of the TZAM6620 alloy pre-aged at $70{ }^{\circ} \mathrm{C}$ for $150 \mathrm{~h}$ taken along the zone axis of [0001]. A number of tiny precipitates are observed. Figure 10 (b) shows a 3D atom map obtained from the TZAM6620 alloy pre-aged at $70{ }^{\circ} \mathrm{C}$ for $150 \mathrm{~h}$. $\mathrm{Zn}$-enriched regions are recognized from the $\mathrm{Zn}$ map, one of which is displayed using an isoconcentration surface of 6.1 at.\% $\mathrm{Zn}$ for better visualization. A ladder diagram analyzed from the selected volume in Fig. 10 (c) shows that the Zn-enriched volume has a composition of $\mathrm{Mg}-1.5 \mathrm{Sn}-17.8 \mathrm{Zn}-6.2 \mathrm{Al}$ (at.\%). The number density of the $\mathrm{Zn}$-rich precipitates was estimated to be $\sim 1.3 \times 10^{23} \mathrm{~m}^{-3}$.

\section{Discussion}

This work has demonstrated the high yield strength of $350 \mathrm{MPa}$ in the peak-aged TZAM5420-0.1Na extruded alloy (Fig. 2 (a)), which is exceptionally high for magnesium wrought alloys that do not contain any rare earth elements. However, the addition of $\mathrm{Na}$ caused significant embrittlement due to the segregation of $\mathrm{Na}$ at grain boundaries. To 
overcome this problem, we have developed the Na-free TZAM6620 alloy. The TZAM6620 alloy exhibited the extraordinary high yield strength over $370 \mathrm{MPa}$ along with the satisfactory ductility up to $14 \%$ by double-aging (Fig. 2 (d). This combination of high strength and ductility is outstanding for wrought magnesium alloy that was processed by ingot metallurgy and subsequent wrought processes. The microstructure characterization suggested that the key for the extraordinary high strength was 1) the inhibition of the grain growth by the $\mathrm{Mn}_{2} \mathrm{Sn}$ precipitates during the solution treatment and 2) uniform dispersion of fine nano-scale $\mathrm{Mg}_{2} \mathrm{Sn}$ and $\operatorname{MgZn}_{2}\left(\beta_{2}{ }^{\prime}\right)$ precipitates by double-aging.

In the TZAM5420-0.1 Na alloy, $\mathrm{Mn}$ and $\mathrm{Na}$ addition contributed to the inhibition of the grain growth during the solution treatment at $450^{\circ} \mathrm{C}$ (Fig. 3). The BSE SEM image and EDS elemental map in Fig. 4 (a) and (b) have shown that the Sn-rich and Al-Mn enriched particles were located along the grain boundaries, suggesting that these particles pinned the grain boundaries and suppressed the grain coarsening. The Auger spectrum of the TZA542-0.1Na alloy in Fig. 4 (c) and (d) has shown the grain boundary segregation of $\mathrm{Na}$ after the solution treatment. Thus, the grain boundary segregation of Na may also contribute to the inhibition of the grain growth by solute-drag like effect during the solution treatment.

$\mathrm{Na}$ also caused the significant precipitate refinement as reported previously [20, 27]. $\mathrm{Na}$ has positive enthalpy of mixing with $\mathrm{Mg}$ [36], and they are virtually immiscible. Since $\mathrm{Sn}$ and $\mathrm{Na}$ has negative enthalpy of mixing, there is a large driving force to co-segregate as $\mathrm{Sn}-\mathrm{Na}$ co-clusters when $\mathrm{Na}$ precipitate out from the matrix prior to the precipitation of $\mathrm{Mg}_{2} \mathrm{Sn}$ phase. The HAADF-STEM and 3DAP results in Fig. 8 (a) - (c) have shown that Na forms co-clusters with $\mathrm{Sn}$ with the size of $\sim 4 \mathrm{~nm}$ and the number density of $6.25 \times 10^{23} \mathrm{~m}^{-3}$ after $6 \mathrm{~h}$ of aging at $160^{\circ} \mathrm{C}$. The $\mathrm{Sn}-\mathrm{Na}$ co-clusters act as heterogeneous nucleation sites for the $\mathrm{Mg}_{2} \mathrm{Sn}$ precipitates, as evidenced by the atom probe tomography in Fig. 9. In contrast, the Na-free 
Mg-Sn-Zn alloys, which forms coarse precipitate microstructure upon aging $[37,38]$, the $\mathrm{Mg}_{2} \mathrm{Sn}$ phase nucleates at the tip of sparsely dispersed $\mathrm{MgZn}_{2}$ type rod-like $\beta_{1}$ ' phase with $\sim 30 \mathrm{~nm}$ in length $[37,38]$. The number density of the Sn-Na co-clusters is much higher than that of the $\beta_{1}{ }^{\prime}$ phase $[37,38]$. Therefore, the extremely refined precipitate microstructure in the peak aged TZAM5420-0.1Na alloy (Fig. 5 (c) and (d)) is attributed to the formation of a high number density of Sn-Na co-clusters in the early stage of aging, Fig. 8.

Although Na-doped TZAM5420-0.1Na alloy showed extraordinary high-strength in the T6 condition, the sample was brittle because of the grain boundary segregation of $\mathrm{Na}$. A similar phenomenon was reported in the Na-doped TZA1031-0.1 Na as-extruded alloy [10]. Thus, we designed a Na-free alloy slightly richer in $\mathrm{Sn}$ and $\mathrm{Zn}$ to enhance the precipitation kinetics by increasing the supersaturation, TZAM6620. In order to suppress the grain growth during the solution heat-treatment, we adopted a lower solution treatment temperature, $350{ }^{\circ} \mathrm{C}$, which is $100^{\circ} \mathrm{C}$ lower than that of TZAM5420-0.1 Na alloy. In this case, the spherical $\mathrm{Mg}_{2} \mathrm{Sn}$ particles that dynamically precipitated during the extrusion were not fully dissolved as shown in Fig. $4(\mathrm{e})$ ). These spherical $\mathrm{Mg}_{2} \mathrm{Sn}$ precipitates worked as a grain growth inhibitor during the solution heat-treatment (Figure 4 (e)), and fine-grained structure was kept in the solution treated TZAM6620 (Fig. 3 (d)).

The TZAM6620 alloy solution treated at $350{ }^{\circ} \mathrm{C}$ can be precipitation strengthened by $\beta_{1}{ }^{\prime}$ and $\beta_{2}{ }^{\prime}$ type precipitates since $\mathrm{Zn}$ was fully dissolved into the matrix. Oh-ishi et al. [32] reported the formation of $\mathrm{Zn}$-rich Guinier Preston (G.P.) zones in a $\mathrm{Mg}-\mathrm{Zn}$ alloy aged at $70^{\circ} \mathrm{C}$ for $50 \mathrm{~h}$. The G.P. zones acted as nucleation sites for $\beta_{1}{ }^{\prime}$ and $\beta_{2}{ }^{\prime}$ phases causing the substantial refinement of the precipitate microstructure. Following this work, we pre-aged the TZAM6620 alloy at $70{ }^{\circ} \mathrm{C}$ for $150 \mathrm{~h}$, and we confirmed that the TZAM6620 alloy shows moderate age hardening in this condition (Fig. 1 (b)), and the Zn-enriched spherical G.P. zone 
are uniformly dispersed as shown in Fig. 10 (b). The number density of the G. P. zones was estimated to be $\sim 1.3 \times 10^{23} \mathrm{~m}^{-3}$, which is equivalent to that of the Na-Sn clusters observed in the TZAM5420-0.1Na. These zones act as nucleation sites for the $\beta_{1}{ }^{\prime}$ precipitates in the 2 nd stage aging, which substantially increased the number of the $\beta_{1}{ }^{\prime}$ precipitates as shown in Fig. 7. In our previous study, the fine dispersion of precipitates was reported to be particularly effective in enhancing the yield strength [36], and the double aged TZAM6620 lead to an extraordinary high yield strength of $370 \mathrm{MPa}$. Since this alloy does not contain $\mathrm{Na}$ that causes the embrittlement of Mg alloys, the newly developed TZAM6620 showed both high strength and good ductility.

Figure 11 summarizes the yield strengths and elongation to failure of various $\mathrm{Mg}$ based wrought alloys fabricated by conventional ingot metallurgy process. The TZAM6620 alloy developed in this work showed better strength-ductility balance compared to previously studied $\mathrm{Mg}-\mathrm{Sn}$ based alloys and the other commercially available wrought alloys such as Mg-Al-Zn and Mg-Zn alloys. Interestingly, the double aged TZAM6620 alloy exhibits almost the same strength, but larger ductility compared to $\mathrm{Mg}-\mathrm{RE}$ alloys strengthened by long period ordered structured (LPSO) phase and fine-grained wrought $\mathrm{Mg}$ alloys fabricated by severe plastic deformation $[2,5,6,46,47]$.

This work has demonstrated that the precipitation hardening can be an effective technique to strengthen wrought magnesium alloys without any significant loss of ductility. However, the hot extrudability of the newly developed TZAM6620 and TZA562 alloys is limited; the TZAM6620 and TZA562 alloys could not be extruded at $2 \mathrm{~mm} / \mathrm{s}$ at $300^{\circ} \mathrm{C}$ unlike the TZA542 and TZAM5420-0.1Na alloys. This is probably because the increased amount of $\mathrm{Zn}$ reduces the melting temperature, causing the hot cracking during extrusion. Double-aging is also needed to increase the strength substantially by the uniform dispersion of fine 
precipitates in the TZAM6620 and TZA562 alloys. They could be a promising candidate as high strength wrought magnesium alloy if the extrudability is improved, and quick and substantial age hardening response is achieved.

\section{Summary}

We have developed a Mg-Sn-Zn-Al based extruded alloy, which can be significantly strengthened by $\mathrm{T} 6$ treatment. The significant strengthening by $\mathrm{T} 6$ treatment is attributed to the inhibition to the grain growth during the solution treatment, and the refinement of the precipitate microstructure.

(1) The trace addition of Na to TZAM542 alloy resulted in the significant yield strength increase from 243 to $347 \mathrm{MPa}$ by $\mathrm{T} 6$ treatment due to the uniform dispersion of fine nanoscale $\mathrm{Mg}_{2} \mathrm{Sn}$ and $\beta_{1}$ 'precipitates and the inhibition to the abrupt grain growth during the solution treatment. However, elongation to failure significantly decreased to $3 \%$ due to the segregation of $\mathrm{Na}$ at grain boundaries.

(2) The refinement of the precipitate microstructure in $\mathrm{Na}$ doped alloy is attributed to the formation of high number density of $\mathrm{Sn}-\mathrm{Na}$ co-clusters, which provided heterogeneous nucleation sites for the refinement of the $\mathrm{Mg}_{2} \mathrm{Sn}$ phase.

(3) To overcome the embrittlement in Na-doped TZAM541+0.1 Na alloy, we have developed a $\mathrm{Sn}$ and $\mathrm{Zn}$ richer alloy, TZAM6620. Low temperature solution treatment at $350^{\circ} \mathrm{C}$ remained the $\mathrm{Mg}_{2} \mathrm{Sn}$ particles that dynamically precipitate during extrusion undissolved, which inhibit the growth of the grains during solution treatment.

(4) Pre-aging of the TZAM6620 alloy caused uniform dispersion of Zn-rich Guinier Preston zones. Subsequent artificial aging caused the uniform dispersion of nanoscale $\beta_{1}{ }^{\prime}$ and $\beta_{2}{ }^{\prime}$ precipitates.

(5) The refined precipitate microstructure lead to the unprecedentedly high yield strength of 
$370 \mathrm{MPa}$ while keeping relatively good elongation to failure of $14 \%$. This alloy shows the best combination of high strength and ductility among wrought magnesium alloys reported so far.

\section{Acknowledgement}

This work was supported by JSPS, Graint-in-Aid for Young Scientists (B), 24760605, Grant-in-Aid for Scientific Research on Innovative Area, "Bulk Nanostructured Metals", 22102002, and JST, Advanced Low Carbon Technology Research and Development Program (ALCA), 12102886. 


\section{References}

[1] Pérez-Prado MT, del Valle MT, Ruano OA, Achieving high strength in commercial Mg cast alloys through large strain rolling, Mat. Lett. 59 (2005) 3299-3303.

[2] W.J. Kim, H.G. Jeong, H.T. Jeong, Achieving high strength and high ductility in magnesium alloys using severe plastic deformation combined with low-temperature aging, Scripta Mater. 61 (2009) 1040-1043.

[3] W.J. Kim, H.W. Lee, S.J. Yoo, Y.B. Park, Texture and mechanical properties of ultrafine-grained Mg-3Al-1Zn alloy sheets prepared by high-ratio differential speed rolling, Mater. Sci. and Eng. A 528 (2011) 874-879.

[4] W.J. Kim, I.B. Park, S.H. Han, Formation of a nanocomposite-like microstructure in Mg-6Al-1Zn alloy, Scripta Mater. 66 (2012) 590-593.

[5] T. Mukai, H. Somekawa, T. Inoue, A. Singh, Strengthening Mg-Al-Zn alloy by repetitive oblique shear strain with caliber roll, Scripta Mater. 62 (2010) 113-116.

[6] D. Orlov, G. Raab, T.T. Lamark, M. Popov, Y. Estrin, Improvement of mechanical properties of magnesium alloy ZK60 by integrated extrusion and equal channel angular pressing, Acta Mater. 59 (2011) 375-385.

[7] T. Honma, C.L. Mendis, K. Hono, S. Kamado, Effect of $\mathrm{Zr}$ addition on the mechanical properties of as-extruded Mg-Zn-Ca-Zr alloys, Mater. Sci. and Eng. A 527 (2010) 2356-2362.

[8] M. Shahzad, L. Wagner, Influence of extrusion parameters on microstructure and texture developments and their effects on mechanical properties of the magnesium alloy AZ80, Mater. Sci. and Eng. A 506 (2009) 141-147.

[9] T.T. Sasaki, K. Yamamoto, T. Honma, S. Kamado, K. Hono, A high-strength Mg-Sn-Zn-Al alloy extruded at low temperature, Scripta Mater. 59 (2008) 1111-1114. 
[10] F.R. Elsayed, T.T. Sasaki, T. Ohkubo, H. Takahashi, S.W. Xu, S. Kamado, K. Hono, Effect of extrusion conditions on microstructure and mechanical properties of microalloyed Mg-Sn-Al-Zn alloys, Mater. Sci. Eng. A 588 (2013) 318-328.

[11] S.H. Park, H.S. Kim, B.S. You, Prediction of grain size and yield strength of Mg-7Sn-1Al-1Zn alloys extruded at various temperatures and speeds, Met. Mater. Int. 20 (2014) 291-296.

[12] C.L. Mendis, J.H. Bae, N.J. Kim, K. Hono, Microstructures and tensile properties of a wtin roll cast and heat-treated Mg-2.4Zn-0.1Zn-0.1Ca-0.1Zr alloy, Scrpipta Mater. 64 (2011) $335-338$.

[13] T. Bhattacharjee, B.C. Suh, T.T. Sasaki, T. Ohkubo, N.J. Kim, K. Hono, High strength and formable $\mathrm{Mg}-6.2 \mathrm{Zn}-0.5 \mathrm{Zr}-0.2 \mathrm{Ca}$ alloy sheet processed by twin roll casting, Mater. Sci. Eng. A 609 (2014)154-160.

[14] Nayeb-Hashemi and J.B. Clark, Phase Diagrams of Binary Magnesium Alloys, ASM International: Materials Park, OH, 1988.

[15] M.M. Avedesian, H. Baker, Magnesium and Magnesium Alloys ASM Specialty Handbook. ASM International, Materials Park, OH, 1999.

[16] J.R. TerBush, M. Setty, N. Stanford, M.R. Barnett, A.J. Morton, J.F. Nie, Microstructure and Mechanical properties of an extruded Mg-Sn-Zn-Na alloy, Proceedings of 9th International Conference on Magnesium Alloys and their Applications, 2012, pp. 579-586.

[17] T.T. Sasaki, J.D. Ju, K. Hono, K.S. Shin, Heat-treatable Mg-Sn-Zn wrought alloy, Scripta Mater. 61 (2009) 80-83.

[18] S. Harosh, L. Miller, G. Levi, M. Bambaerger, Microstructure and properties of Mg5.6\%Sn-4.4\%Zn-2.1\%Al alloy, J. Mater. Sci. 42 (2007) 9983-9989.

[19] C.L. Mendis, C.J. Bettles, M.A. Gibson, C.R. Hutchinson, An enhanced age hardening 
response in Mg-Sn based alloys containing Zn, Mater. Sci. Eng. A 435-436 (2006) 163-171. [20] C.L. Mendis, C.J. Bettles, M.A. Gibson, S. Grosse, C.R. Hutchinson, Refinement of precipitate distributions in an age-hardenable $\mathrm{Mg}-\mathrm{Sn}$ alloy through microalloying, Philos. Mag. Lett. 86 (2006) 443-456.

[21] T.T. Sasaki, K. Oh-ishi, T. Ohkubo, K. Hono, Enhanced age hardening response by the addition of Zn in Mg-Sn alloys, Scripta Mater. 55 (2006) 251-254.

[22] T.T. Sasaki, K. Oh-ishi, T. Ohkubo, K. Hono, Effect of double aging and microalloying on the age hardening behavior of a Mg-Sn-Zn alloy, Mater. Sci. Eng. A 530 (2011) 1-8.

[23] X.F. Huang, Q.Z. Zhang, Improved age-hardening behavior of Mg-Sn-Mn alloy by adittion of Ag and Zn, Mater. Sci. Eng. A 552 (2012) 211-221.

[24] Z.Z. Shi, W.Z. Zhang, Enhanced age-hardening response and microstructure study of an Ag-modified Mg-Sn-Zn based alloy, Philos. Mag. Lett. 93 (2013) 473-480.

[25] F.R. Elsayed, T.T. Sasaki, C.L. Mendis, T. Ohkubo, K. Hono, Compositional optimization of Mg-Sn-Al alloys for high age hardening response, Mater. Sci. Eng. A 566 (2013) 22-29.

[26] G. Zhang, J. Chen, H. Yan, S. Bin, X. He, M. Ran, Effects of artificial aging on microstructure and mechanical properties of the Mg-4.5Zn-4.5Sn-2Al alloy, J. Alloys Comp. $592(2014) 250-257$.

[27] F.R. Elsayed, T.T. Sasaki, C.L. Mendis, T. Ohkubo, K. Hono, Significant enhancement of the age-hardening response in Mg-10Sn-3Al-1Zn alloy by $\mathrm{Na}$ microalloying, Scripta Mater. $68(2013) 797-800$.

[28] T. T. Sasaki, T. Ohkubo and K. Hono, Age hardening behavior of Mg-1.2Sn-1.7Zn alloy containing Al, Magnesium Technology 2012, S.N. Mathaudhu, W.H. Sillekens, N.R. Neelameggham (Eds.), The Minerals, Metals \& Materials Society (TMS), 2012, pp. 181-185. 
[30] J.R. Terbush, N. Stanford, J.F. Nie, M.R. Barnett, Na Partitioning during thermomechanical processing of an Mg-Sn-Zn-Na alloy, Metall. Mater. Trans. A 44A (2013) $5216-5225$.

[29] Y. Yoshida, L. Cisar, T. Sekine, S. Kamado, Y. Kojima, Effect of Mn content on tensile properties of rolled AZ31 magnesium alloy sheet, J. Jpn. Inst. Metals 68 (2004) 412-417.

[30] P. Cao, M. Qian, D.H. StJohn, Effect of manganese on grain refinement of Mg-Al based alloys, Scripta Mater. 54 (2006) 1853-1858.

[31] X. Huang, K. Suzuki, A. Watazu, I. Shigematsu, N. Saito, Effects of manganese addition on microstructure and press formability of hot-rolled Mg-Al-Zn alloy sheets, J. Mater. Res. 23 (2008) 3029-3039.

[32] K. Oh-ishi, K. Hono, K.S. Shin, Effect pre-aging and Al addition on age-hardening and microstructure in Mg-6wt.\%Zn alloys, Mater. Sci. Eng. A 496 (2008) 425-433.

[33] E.O. Hall, The age-hardening characteristics of two magnesium-zinc alloys, J. Inst. Metals 96 (1968) 21-27.

[34] J.S. Chun, J.G. Byrne, Precipitate strengthening mechanisms in magnesium zinc alloy single crystals, J. Mater. Sci. 4 (1969) 861-872.

[35] L.Y. Wei, G.L. Dunlop, H. Westengen, Precipitation hardening of Mg-Zn and Mg-Zn-RE alloys, Metall. Mater. Trans. A 26A (1995) 1705-1716.

[36] F.R. de Boer, R. Boom, W.C.M. Mattens, A.R. Miedema, A.K. Niessen, Cohesion in Metals - Transition Metal Alloys (Cohesion and structure), North Holland, Amsterdam, 1989. [37] A. Gorny, A. Katsman, Precipitation- and stress-influenced coarsening in Mg-based MgZn-Sn-Y and Mg-Zn-Sn-Sb alloys, J. Mater. Res. 23 (2008) 1228-1236.

[38] T.T. Sasaki, K. Oh-ishi, T. Ohkubo, K. Hono, Effect of double aging and microalloying on the age hardening behavior of a Mg-Sn-Zn alloy, Mater. Sci. Eng. A 530 (2011) 1-8. 
[39] K. Hono, C.L. Mendis, T.T. Sasaki, K. Oh-ishi, Towards the development of heat-treatable high-strength wrought Mg alloys, Scripta Mater. 63 (2010) 710-715.

[40] S.S. Park, W.N. Tang, B.S. You, Microstructure and mechanical properties of an indirect-extruded Mg-8Sn-1Al-1Zn alloy, Mater. Lett. 64 (2010) 31-34.

[41] Y.K. Kim, S.W. Sohn, D.H. Kim, W.T. Kim, D.H. Kim, Role of icosahedral phase in enhancing the strength of Mg-Sn-Zn-Al alloy, J. Alloys Comp. 549 (2013) 46-50.

[42] H.T. Son, J.B. Lee, H.G. Jeong, T.J. Konno, Effects of Al and Zn additions on mechanical properties and precipitation behaviors of $\mathrm{Mg}-\mathrm{Sn}$ alloy system, Mater. Lett. 65 (2011) 1966-1969.

[43] W.L. Cheng, S.S. Park, B.S. You, B.H. Koo, Microstructure and mechanical properties of binary Mg-Sn alloys subjected to indirect extrusion, Mater. Sci. and Eng. A 527 (2010) $4650-4653$.

[44] S.H. Park, Y.M. Kim, C.D. Yim, H.S. Kim, B.S. You, Microstructure and mechanical properties of as-extruded Mg-Sn-Al-Zn alloys, Magnesium Technology 2012, S.N. Mathaudhu, W.H. Sillekens, N.R. Neelameggham (Eds.), The Minerals, Metals \& Materials Society (TMS), 2012, pp. 439-442.

[45] H.D. Zhao, G.W. Qin, Y.P. Ren, W.L. Pei, D. Chen, Y. Guo, Microstructure and tensile properties of as-extruded Mg-Sn-Y alloys, Trans. Nonferrous. Soc. China 20 (2010) s493-s497.

[46] W.L. Cheng, H.S. Kim, B.S. You, B.H. Koo, S.S. Park, Strength and ductility of novel Mg-8Sn-1Al-1Zn alloys extruded at different speeds, Mat. Lett. 65 (2011) 1525-1524.

[47] S. Kamado, H. Ohara, Y. Kojima, Advanced Manufacturing Technologies of Magnesium Alloys, CMC Publishing, Tokyo, 2005.

[48] C.L. Mendis, K. Oh-ishi, Y. Kawamura, T. Honma, S. Kamado, K. Hono. Acta Mater. 57 
(2009) 749-760.

[49] M. Yamasaki, K. Hashimoto, K. Hagihara, Y. Kawamura, Effect of multimodal microstructure evolution on mechanical properties of Mg-Zn-Y extruded alloy, Acta Mater. 59 (2011) 3646-3658.

[50] Y. Kawamura, M. Yamasaki, Formation and mechanical properties of Mg97Zn1RE2 alloys with long-period stacking ordered structure, Mater. Trans. 48 (2007) 2986-2992. 
Table 1: Alloy nomenclature and compositions of samples used in this work

\begin{tabular}{lll}
\hline & \multicolumn{1}{c}{ wt. $\%$} & \multicolumn{1}{c}{ at.\% } \\
\hline TZA542 & $\mathrm{Mg}-5.4 \mathrm{Sn}-4.2 \mathrm{Zn}-2.0 \mathrm{Al}$ & $\mathrm{Mg}-1.2 \mathrm{Sn}-1.7 \mathrm{Zn}-2.0 \mathrm{Al}$ \\
TZAM5420 & $\mathrm{Mg}-5.4 \mathrm{Sn}-4.2 \mathrm{Zn}-2.0 \mathrm{Al}-0.2 \mathrm{Mn}$ & $\mathrm{Mg}-1.2 \mathrm{Sn}-1.7 \mathrm{Zn}-2.0 \mathrm{Al}-0.1 \mathrm{Mn}$ \\
TZA542-0.1Na & $\mathrm{Mg}-5.4 \mathrm{Sn}-4.2 \mathrm{Zn}-2.0 \mathrm{Al}-0.1 \mathrm{Na}$ & $\mathrm{Mg}-1.2 \mathrm{Sn}-1.7 \mathrm{Zn}-2.0 \mathrm{Al}-0.1 \mathrm{Na}$ \\
TZAM5420-0.1Na & $\mathrm{Mg}-5.4 \mathrm{Sn}-4.2 \mathrm{Zn}-2.0 \mathrm{Al}-0.2 \mathrm{Mn}-0.1 \mathrm{Na}$ & $\mathrm{Mg}-1.2 \mathrm{Sn}-1.7 \mathrm{Zn}-2.0 \mathrm{Al}-0.1 \mathrm{Mn}-0.1 \mathrm{Na}$ \\
TZA562 & $\mathrm{Mg}-5.4 \mathrm{Sn}-5.9 \mathrm{Zn}-2.0 \mathrm{Al}$ & $\mathrm{Mg}-1.2 \mathrm{Sn}-2.4 \mathrm{Zn}-2.0 \mathrm{Al}$ \\
TZAM6620 & $\mathrm{Mg}-6.6 \mathrm{Sn}-5.9 \mathrm{Zn}-2.0 \mathrm{Al}-0.2 \mathrm{Mn}$ & $\mathrm{Mg}-1.5 \mathrm{Sn}-2.4 \mathrm{Zn}-2.0 \mathrm{Al}-0.1 \mathrm{Mn}$ \\
\hline
\end{tabular}

Table 2: Tensile properties of as-extruded and T6 treated TZA542, TZAM5420, TZA542-0.1Na and TZAM5420-0.1Na alloys.

\begin{tabular}{|c|c|c|c|c|c|c|c|c|}
\hline \multirow{2}{*}{ Sample } & \multicolumn{4}{|c|}{ Tensile } & \multicolumn{3}{|c|}{ Compression } & \multirow{2}{*}{$\sigma_{C Y S} / \sigma_{T Y S}$} \\
\hline & Condition & $\sigma_{T Y S}, \mathrm{MPa}$ & $\sigma_{U T S}, \mathrm{MPa}$ & $\varepsilon_{T}, \%$ & $\sigma_{C Y S}, \mathrm{MPa}$ & $\sigma_{C S}, \mathrm{MPa}$ & $\varepsilon_{C}, \%$ & \\
\hline \multirow{2}{*}{ TZA542 } & As-Extruded & 184 & 311 & 11 & 170 & 451 & 13.8 & 0.92 \\
\hline & T6 & 229 & 303 & 6 & 141 & 420 & 14.4 & 0.62 \\
\hline \multirow{2}{*}{ TZAM5420 } & As-Extruded & 182 & 324 & 24 & 168 & 419 & 13.8 & 0.92 \\
\hline & T6 & 186 & 292 & 19 & 142 & 426 & 14.6 & 0.76 \\
\hline \multirow{2}{*}{ TZA542-0.1Na } & As-Extruded & 203 & 302 & 11 & 197 & 459 & 12.2 & 0.97 \\
\hline & $\mathrm{T} 6$ & 257 & 301 & 4 & 200 & 451 & 10.4 & 0.78 \\
\hline \multirow{2}{*}{ TZAM5420-0.1Na } & As-Extruded & 243 & 324 & 10 & 245 & 451 & 10.9 & 1.01 \\
\hline & $\mathrm{T} 6$ & 347 & 369 & 3 & 225 & 505.4 & 11.8 & 0.65 \\
\hline
\end{tabular}

Table 3: Tensile properties of TZA562 and TZAM6620 alloys. Note that the condition for the double aging condition is $70{ }^{\circ} \mathrm{C} / 150 \mathrm{~h}$ and $140{ }^{\circ} \mathrm{C}$ to the peak hardness.

\begin{tabular}{|c|c|c|c|c|c|c|c|c|}
\hline \multirow{2}{*}{ Sample } & \multicolumn{4}{|c|}{ Tensile } & \multicolumn{3}{|c|}{ Compression } & \multirow{2}{*}{$\sigma_{C Y S} / \sigma_{T Y S}$} \\
\hline & Condition & $\sigma_{T Y S}, \mathrm{MPa}$ & $\sigma_{U T S}, \mathrm{MPa}$ & $\varepsilon_{T}, \%$ & $\sigma_{C Y S}, \mathrm{MPa}$ & $\sigma_{C S}, \mathrm{MPa}$ & $\varepsilon_{C}, \%$ & \\
\hline \multirow{3}{*}{ TZA562 } & As-Extruded & 243 & 351 & 21 & 234 & 467 & 11.4 & 0.96 \\
\hline & Single / $140^{\circ} \mathrm{C}$ & 255 & 350 & 20 & 237 & 522 & 11.9 & 0.93 \\
\hline & Double aged & 346 & 385 & 15 & 277 & 532 & 12.4 & 0.80 \\
\hline \multirow{3}{*}{ TZAM6620 } & As-Extruded & 247 & 349 & 16 & 253 & 473 & 11.2 & 1.02 \\
\hline & Single / $140^{\circ} \mathrm{C}$ & 267 & 347 & 13 & 248 & 506 & 12.6 & 0.93 \\
\hline & Double aged & 370 & 399 & 14 & 307 & 521 & 9.8 & 0.83 \\
\hline
\end{tabular}




\section{Figure Captions}

Figure 1: Variations in Vickers hardness as a function aging time at $160^{\circ} \mathrm{C}$ for (a) $\mathrm{TZA} 542$, TZAM5420, TZA542-0.1Na and TZAM5420-0.1 Na alloys solution treated at $450^{\circ} \mathrm{C}$, and (b) age-hardening curves for TZA542, TZA562 and TZAM6620 alloys aged at various solution treatment and aging temperatures. Note that Ext., S.T. and P.A. stand for Extruded, Solution Treated and Pre-Aged, respectively.

Figure 2: Nominal stress-strain curves obtained from as-extruded and peak aged samples. (a) TZA542 and TZAM5420 alloys, (b): TZA542-0.1 Na and TZAM5420-0.1 Na alloys, (c) TZA562 alloy, and (d) TZAM6620 alloy.

Figure 3: Inverse pole figure maps of as-extruded (a) TZA542, (b) TZAM5420, (c) TZAM5420-0.1Na, (d) TZAM6620 alloys, and the solution treated (e) TZA542, (f) TZAM5420, (g) TZAM5420-0.1Na, (h) TZAM6620 alloys. These images are taken from a plane parallel to the extrusion direction. Insets in (a) through (d) and (g) and (h) are the (0001) pole figure analyzed from the normal plane to the extrusion direction.

Figure 4: (a) A backscattered electron SEM image and (b) corresponding EDS elemental map of Sn, Al and Mn obtained from the solution treated TZAM5420-0.1Na alloy. (c) and (d) are the fracture surface and Auger spectrum obtained from the fracture surface obtained from the solution treated TZA542-0.1 Na alloy. (e) is a bright field TEM image obtained from the TZAM6620 alloy solution treated at $350{ }^{\circ} \mathrm{C}$. (f) the micro beam diffraction pattern taken from one of the spherical precipitates located along the grain boundary.

Figure 5: Bright field TEM images of the peak aged TZA542 alloy taken from the zone axes of (a) [1010] and (b) [0001]. (c) and (d) are the bright field TEM images of the peak aged TZAM5420-0.1Na alloy taken from the zone axes of [1120] and [0001]. 
Figure 6: (a) is the HAADF-STEM image obtained from precipitates in contact with each other. (b) and (c) are the micro-beam diffraction patterns taken from precipitates indicated by black and white arrows in (a). (d) and (e) are 3D atom map including $\mathrm{Sn}, \mathrm{Zn}, \mathrm{Al}$ and $\mathrm{Na}$ and ladder diagram analyzed from the volume indicated in (d).

Figure 7: Bright field TEM images taken from the zone axes of (a) [10 $\overline{1} 0]$ and (b) [0001] of the peak aged TZAM6620 alloy during single aging at $140{ }^{\circ} \mathrm{C}$. (c) and (d) are the microbeam diffraction patterns taken from the lod and blocky shaped precipitates from [11 20$]$ zone axis. (e) and (f) are the ones taken from the zone axes of [10 $\overline{1} 0]$ and (b) [0001] of the peak aged TZAM6620 alloy during double aging.

Figure 8: (a) HAADF-STEM image and (b) 3D atom map of $\mathrm{Sn}, \mathrm{Zn}, \mathrm{Al}$ and $\mathrm{Na}$ obtained from the TZAM5420-0.1Na alloy aged for $6 \mathrm{~h}$ at $160{ }^{\circ} \mathrm{C}$. Inset figure in (a) is the magnified HAADF-STEM image taken from a brightly imaged nanoparticle. (c) is the ladder diagram analyzed from the volume (blue) in (b).

Figure 9: (a) and (b) are the HAADF-STEM images, 3D atom map of $\mathrm{Sn}, \mathrm{Zn}, \mathrm{Al}$ and $\mathrm{Na}$ obtained from the TZAM5420-0.1Na alloy aged for $16 \mathrm{~h}$ at $160^{\circ} \mathrm{C}$. (c) and (d) are the ladder diagram analyzed from the volume with blue and pink in (b).

Figure 10: (a) Bright field TEM image taken from [0001] zone axis. (b) is the 3D atom map obtained from the pre-aged TZAM6620 alloy. Ladder diagram in (c) is analyzed from the selected volume (blue) including Zn-enriched phase in (b).

Figure 11: Yield strength and elongation to failure of various magnesium based extruded alloys. Note that As-Ext. and Aged stand for as-extruded sample, and peak aged sample, respectively. Note that $\mathrm{F}$ in legends strands for as-fabricated samples, which means 
as-extruded or as-rolled samples. 


\section{Figure 1}

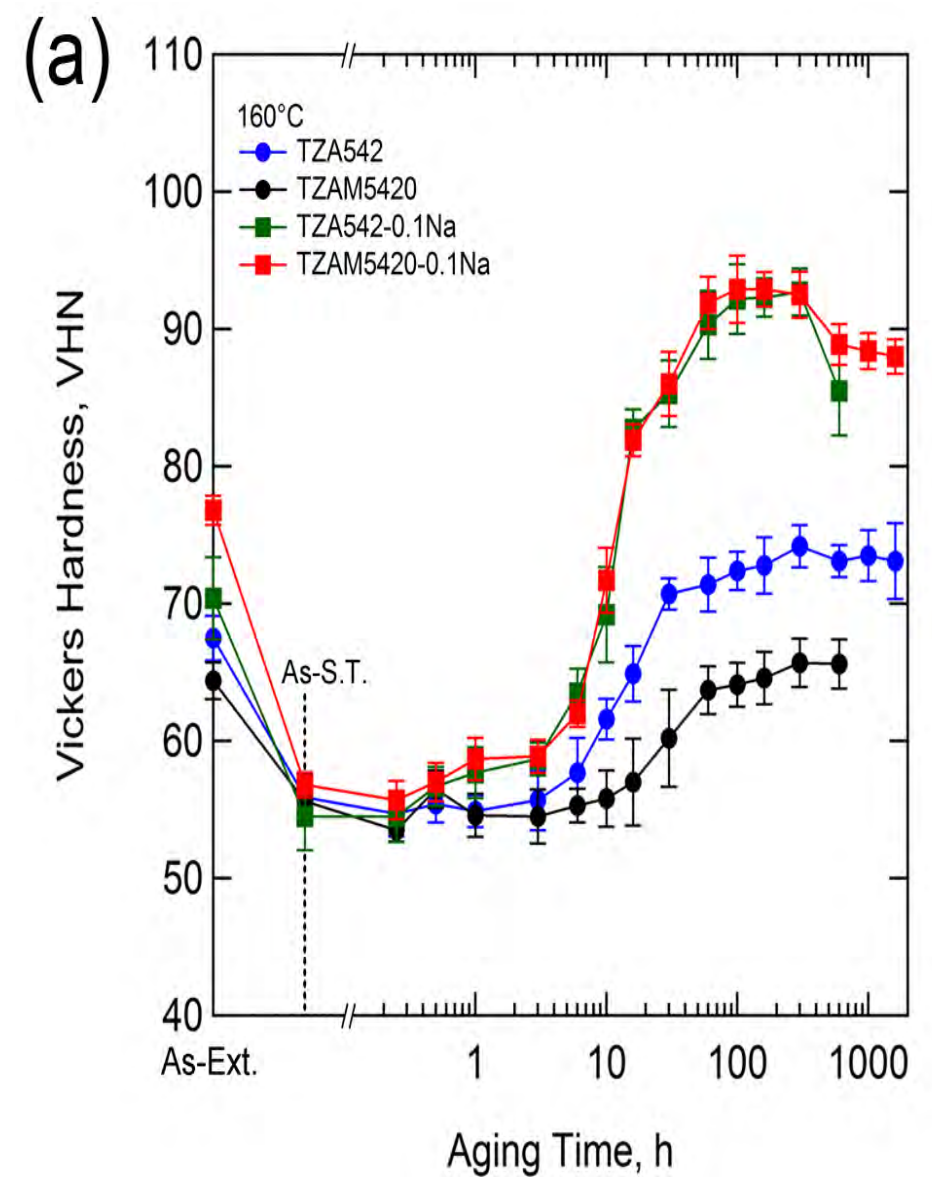

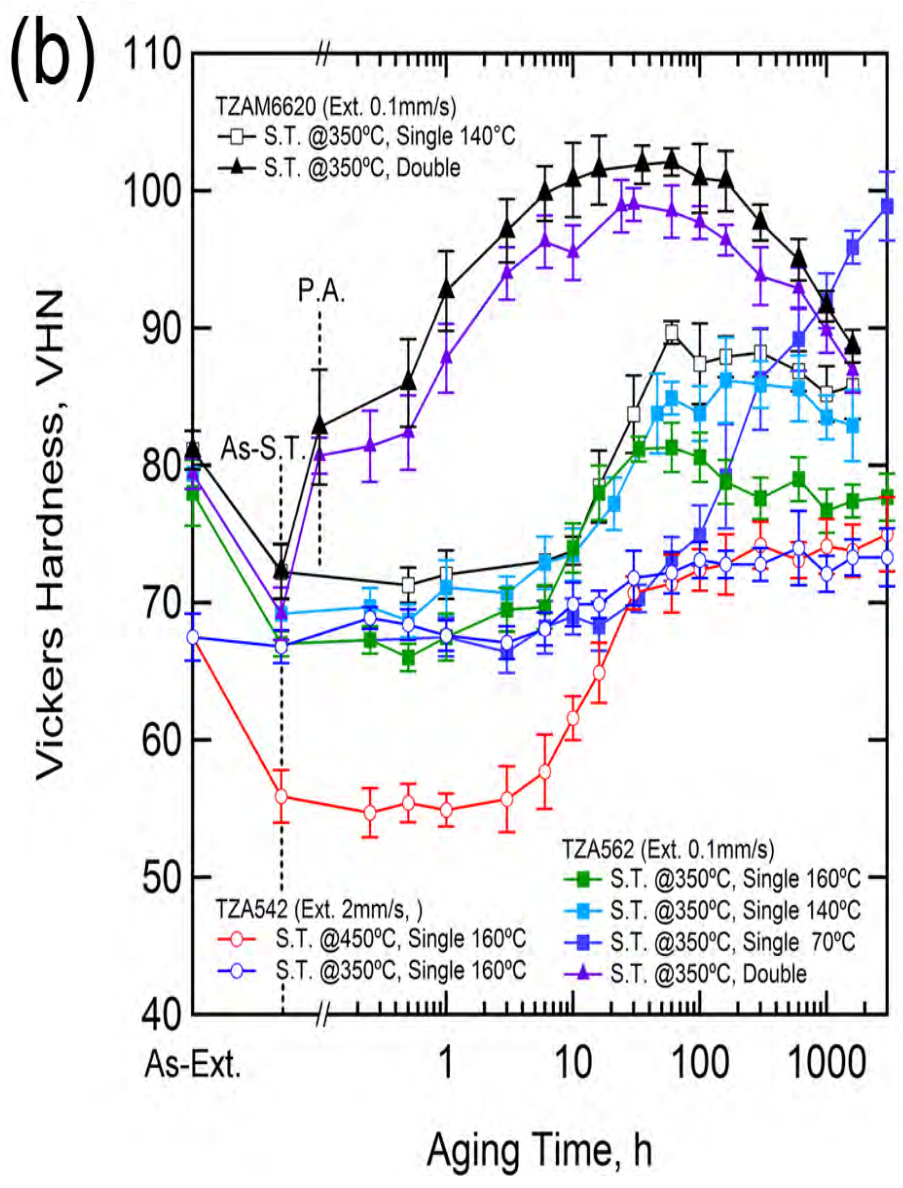




\section{Figure 2}
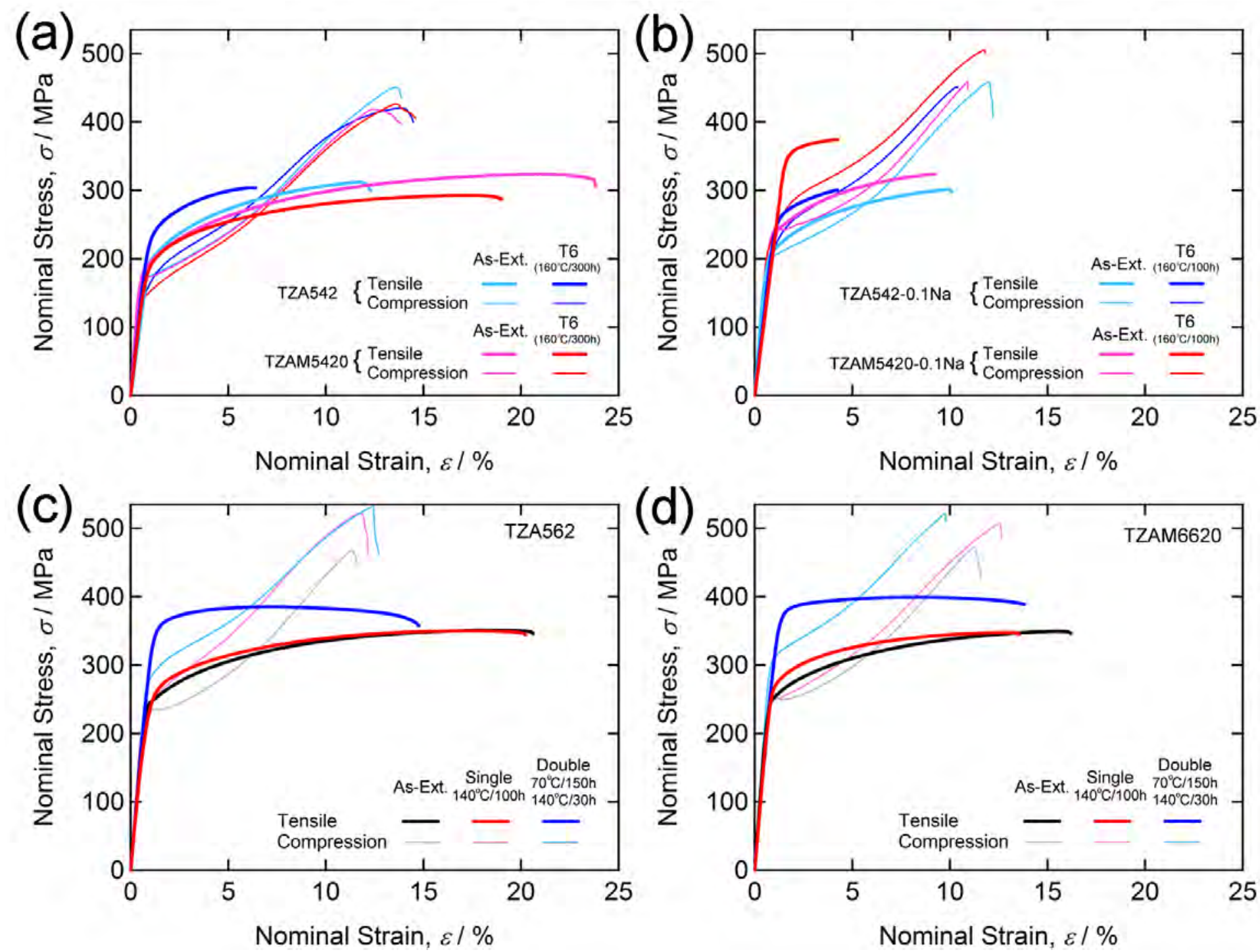


\section{Figure 3}

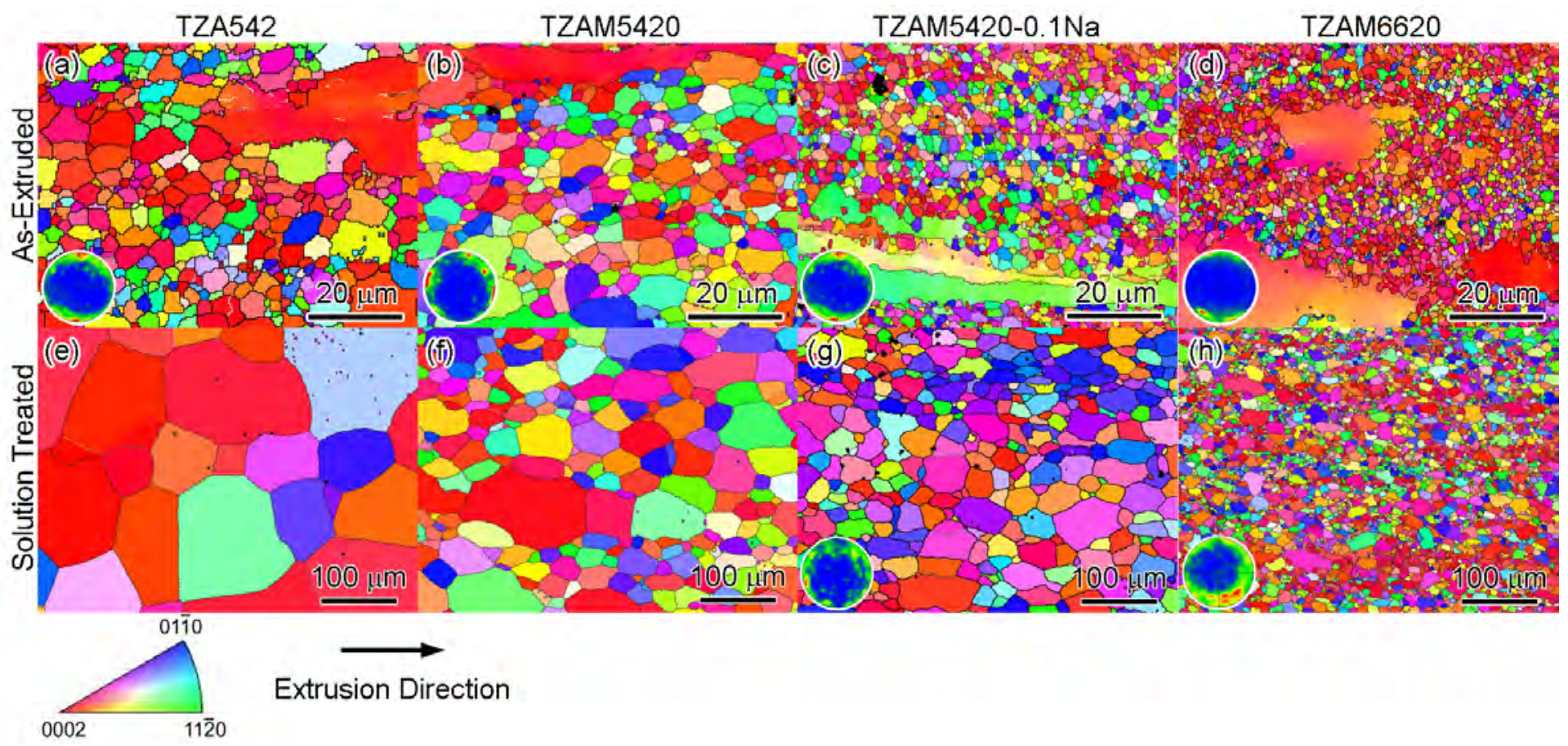


Figure 4




Figure 5

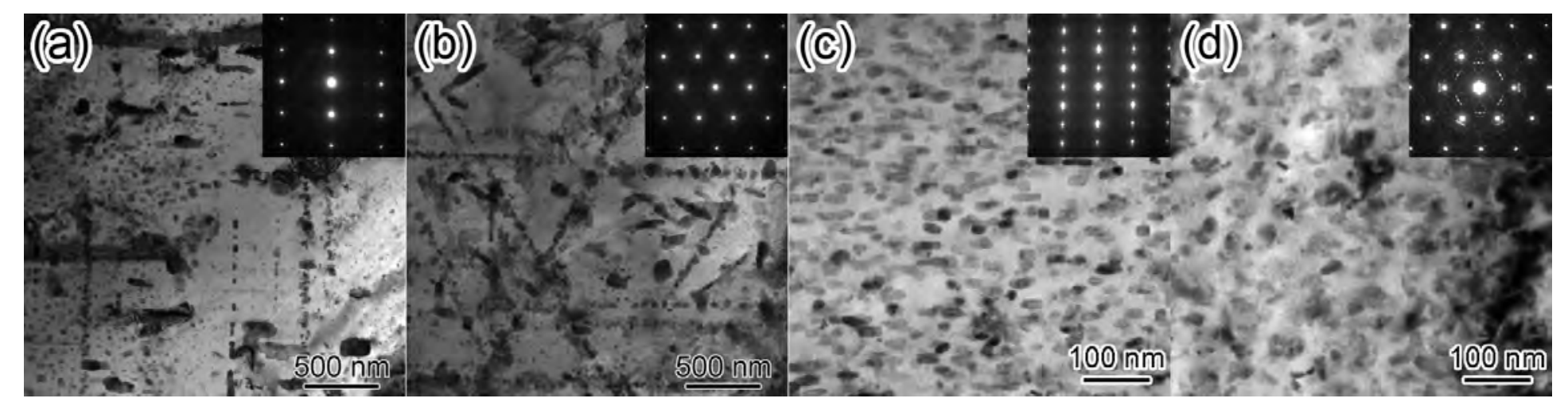


Figure 6
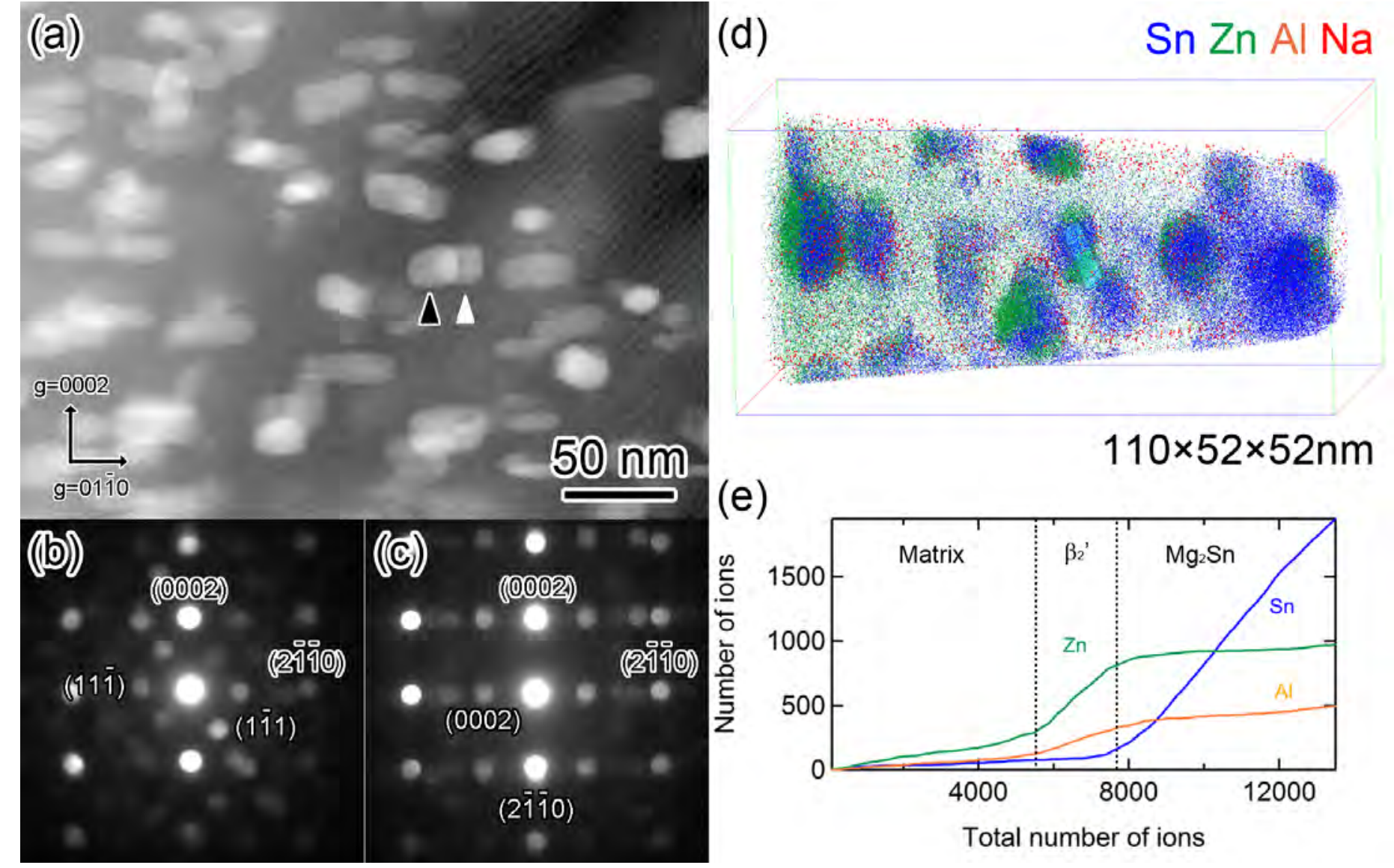

(e)

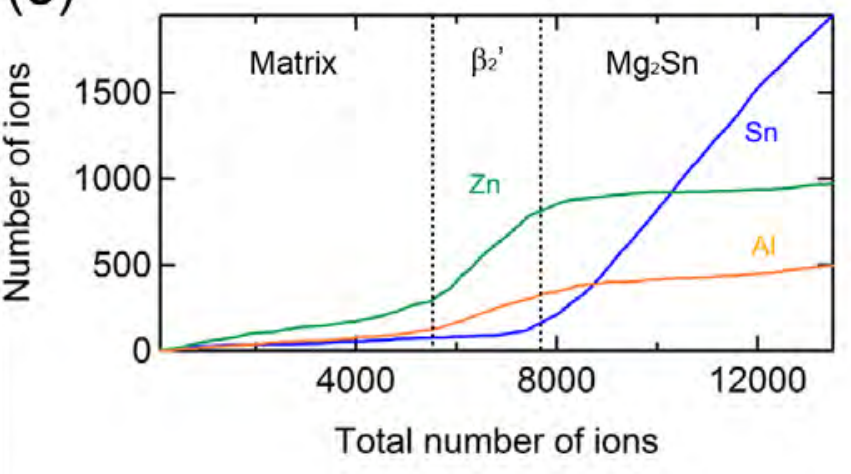




\section{Figure 7}

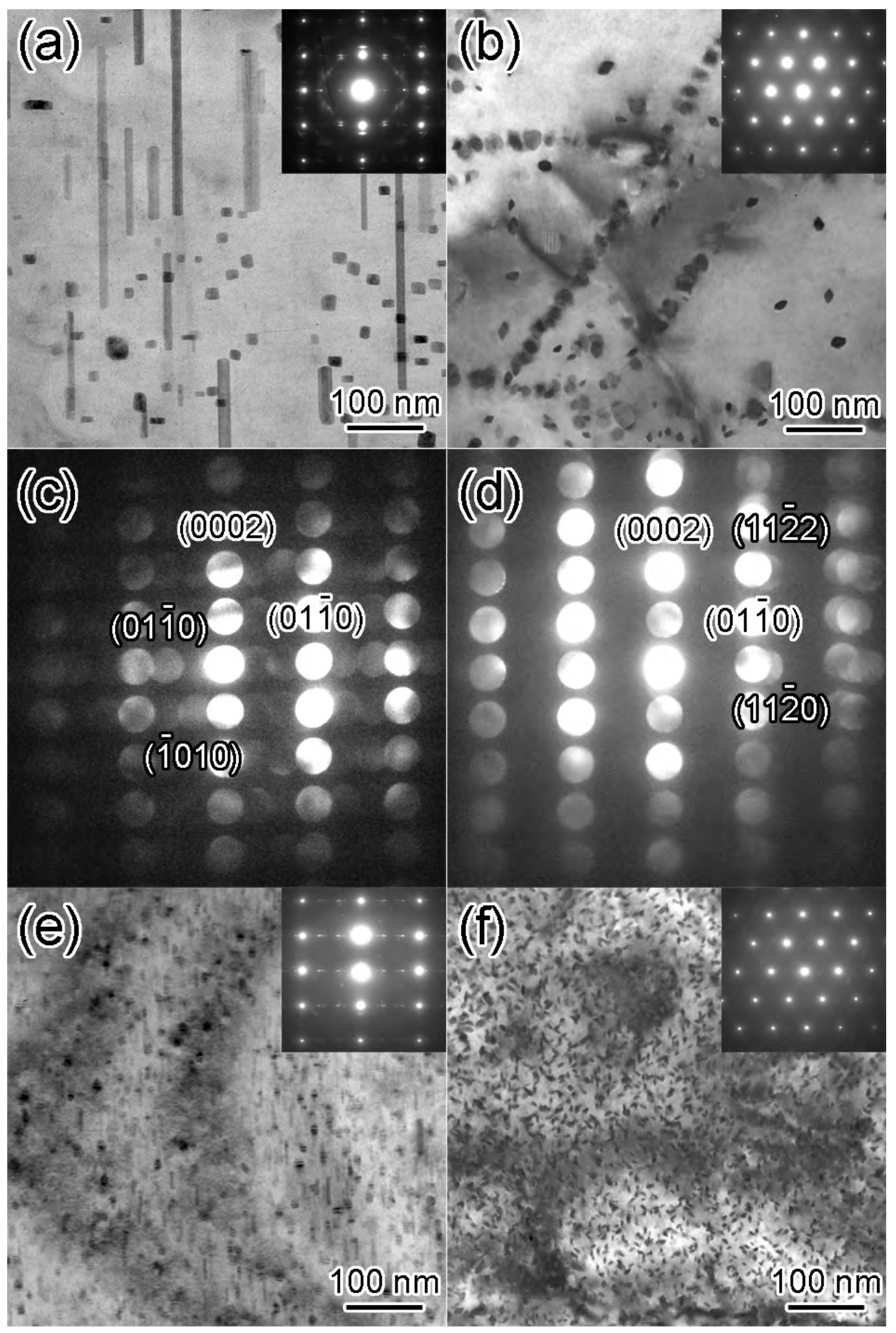


Figure 8
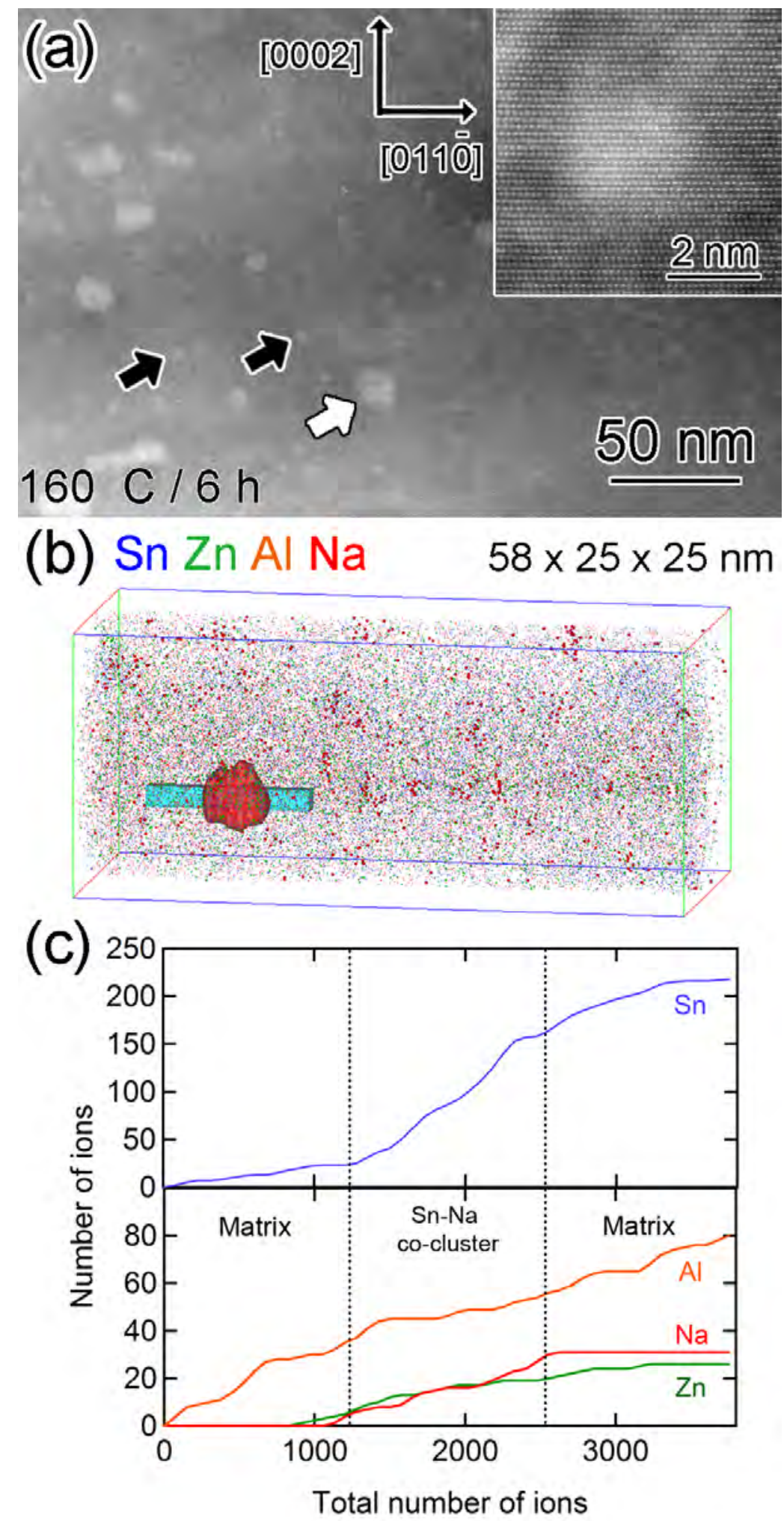


\section{Figure 9}
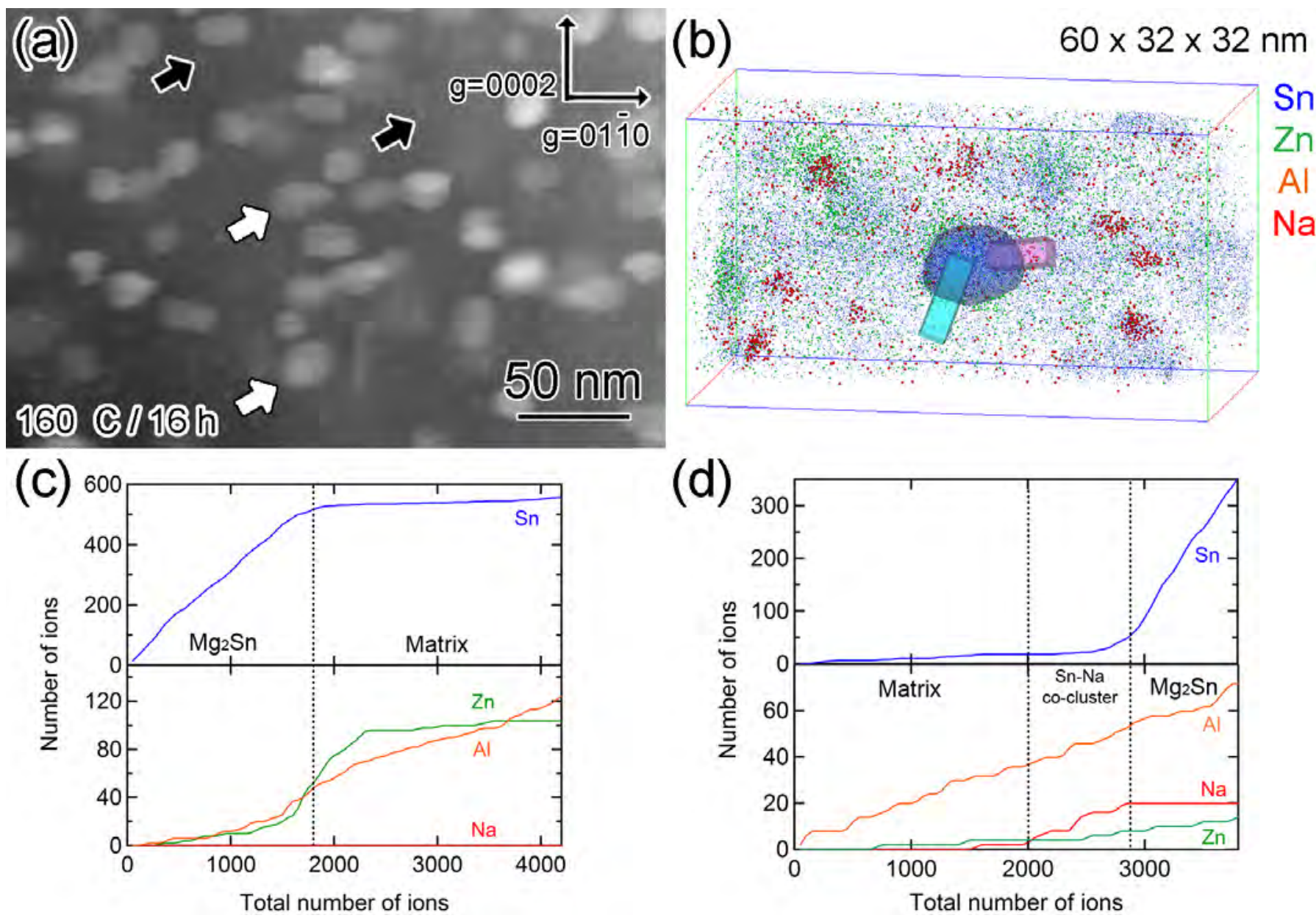
Figure 10
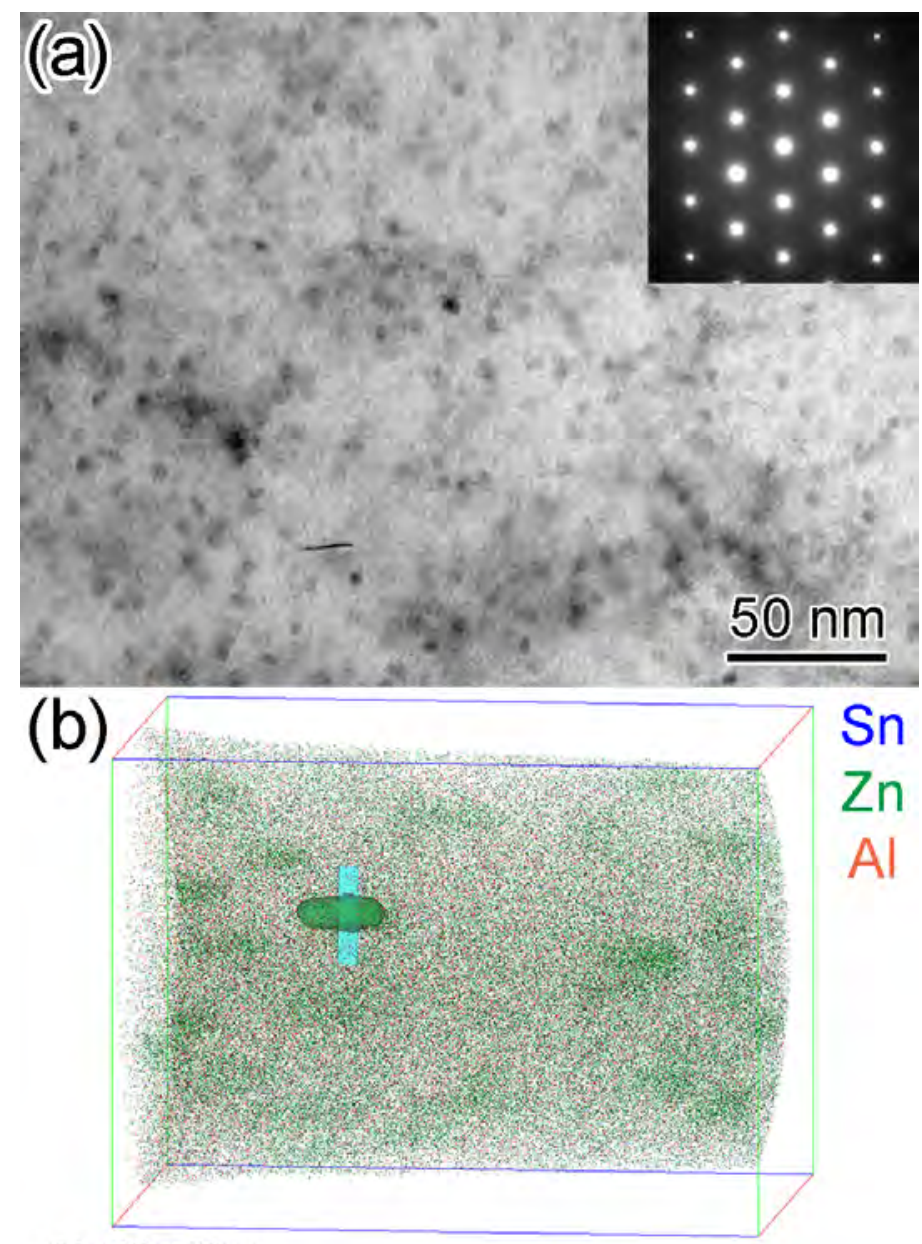

$99 \times 72 \times 72 \mathrm{~nm}$






\section{Figure 11}

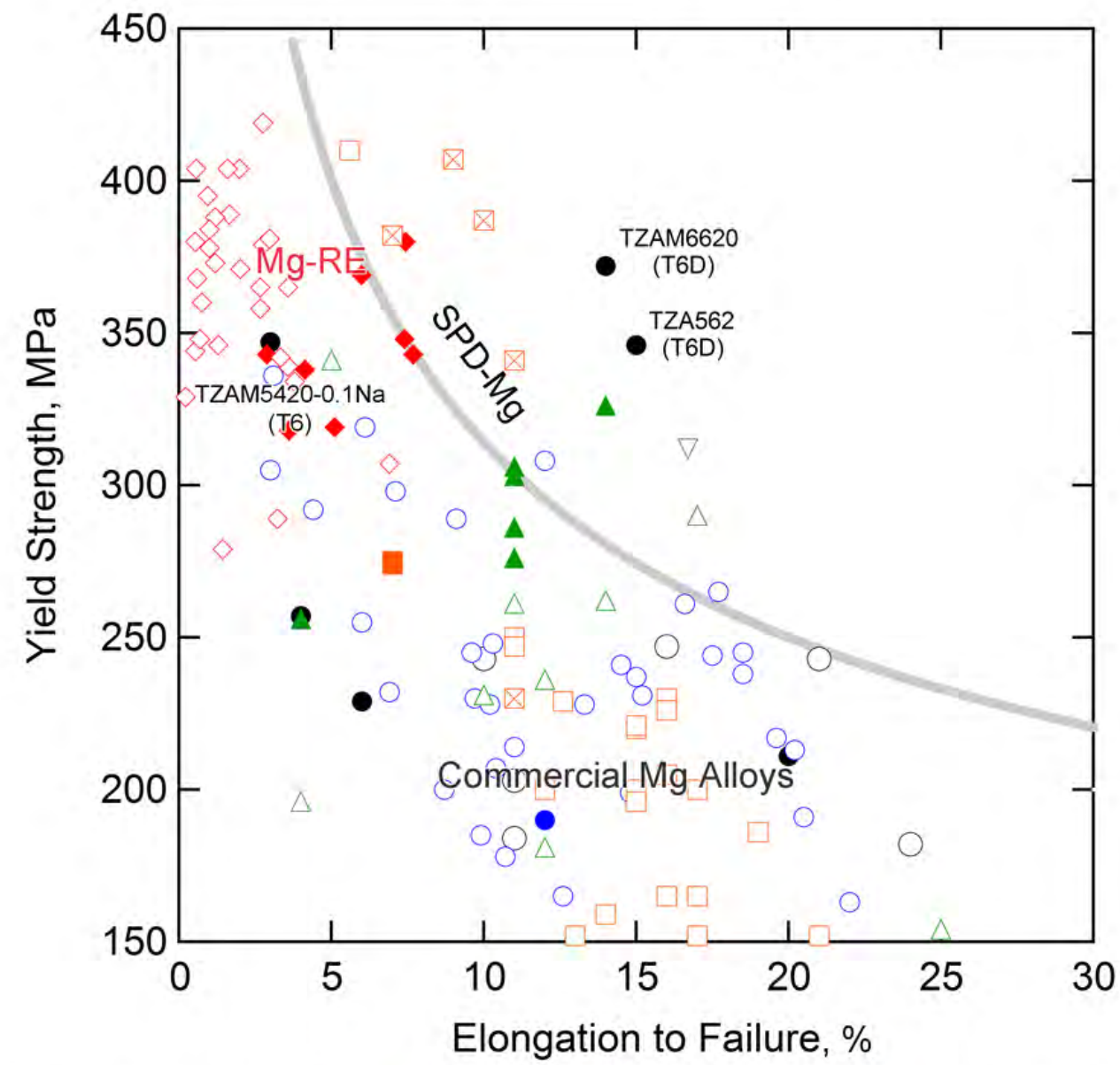

O This work (As-Ext.)

- This work (Aged)

- Mg-Sn-Zn (F) [9-11, 16, 17, 40-46]

- Mg-Sn (Aged) [17]
$\triangle M g-Z n(F)$
$\square \quad \mathrm{Mg}-\mathrm{Al}(\mathrm{F})$ [15, 47, 48]
$\Delta \quad M g-Z n$ (Aged) $[15,47,48]$
$\nabla \mathrm{Mg}-\mathrm{Zn}$ (SPD)
[6]
- Mg-Zn-RE (w/LPSO) $[15,47]$ $[49,50]$
- $\mathrm{Mg}-\mathrm{Al}$ (Aged) $\diamond \mathrm{Mg}-\mathrm{Zn}-\mathrm{RE}$ (w/oLPSO) [15, 47] $[49,50]$ $\mathrm{Mg}-\mathrm{Al}$ (SPD)
$[2,5]$ 


\section{Graphical Abstract}

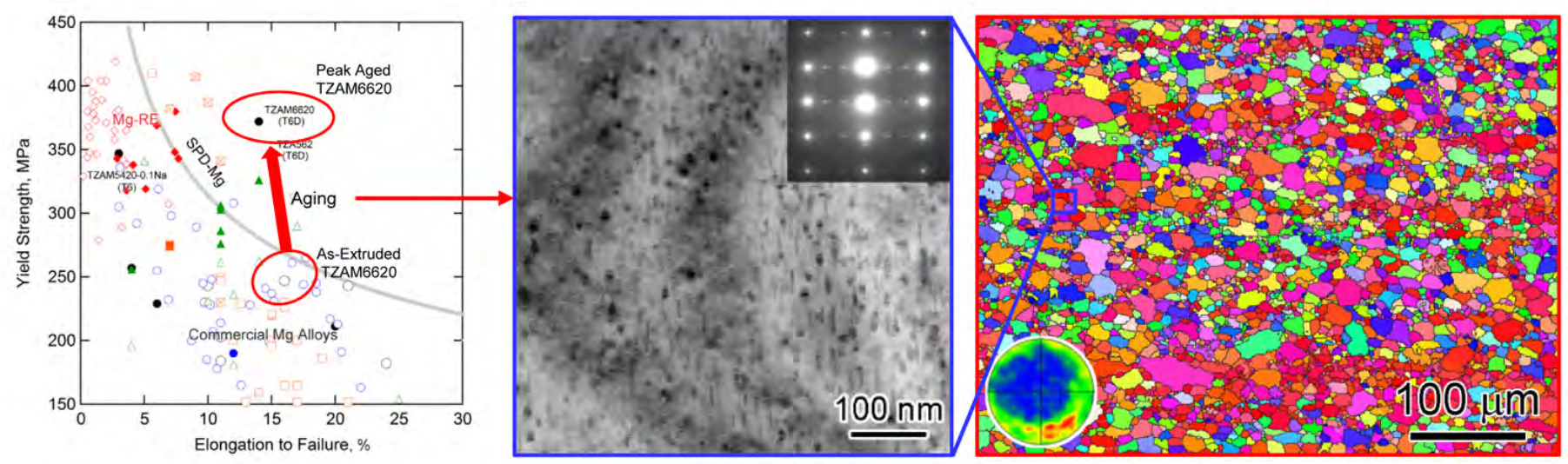

